\title{
The Engineering Economist
}

A Journal Devoted to the Problems of Capital Investment

ISSN: 0013-791X (Print) 1547-2701 (Online) Journal homepage: http://www.tandfonline.com/loi/utee20

\section{Towards Closing the Loop Between Infrastructure Investments and Societal and Economic Impacts}

\section{Ali Z. Rezvani, Walter Kemmsies, Ajith Kumar Parlikad \& Mohsen A Jafari}

To cite this article: Ali Z. Rezvani, Walter Kemmsies, Ajith Kumar Parlikad \& Mohsen A Jafari (2015): Towards Closing the Loop Between Infrastructure Investments and Societal and Economic Impacts, The Engineering Economist, DOI: 10.1080/0013791X.2015.1065358

To link to this article: http://dx.doi.org/10.1080/0013791X.2015.1065358

View supplementary material $₫$

\section{冓 Accepted online: 29 Jul 2015.}

Submit your article to this journal $₫$

Џ Article views: 15

Q View related articles $\sqsubset$

View Crossmark data ¿ 


\title{
ACCEPTED MANUSCRIPT
}

$<$ RRH $>$ Infrastructure Investment; Dynamical Models $</$ RRH $>$

Towards closing the loop between infrastructure investments and societal and economic impacts

\author{
Ali Z. Rezvani, ${ }^{1}$ Walter Kemmsies, ${ }^{1}$ Ajith Kumar Parlikad, ${ }^{2}$ and Mohsen A Jafari ${ }^{3}$ \\ ${ }^{1}$ Moffatt \& Nichol, New York, New York \\ ${ }^{2}$ Institute for Manufacturing, University of Cambridge, Cambridge, United Kingdom \\ ${ }^{3}$ Rutgers University, Industrial and Systems Engineering, Piscataway, New Jersey \\ Address correspondence to Mohsen A Jafari, Rutgers University, Industrial and Systems \\ Engineering, 96 Frelinghuysen Road, Piscataway, NJ 08854. E-mail: majafari123@gmail.com \\ Color versions of one or more of the figures in the article can be found online at \\ www.tandfonline.com/utee.
}

The long-term value proposition of transportation infrastructure investments can be significantly distorted if the short term effects of spatial externalities on land-use patterns, economic expansions, and migration patterns are not properly included in the analysis. Some of these effects occur over a short period of time and soon after the investment materializes, while others take longer and follow more steady patterns. In this paper, we develop a novel dynamical model of a primal society with constructs that are specifically geared toward transportation infrastructure expansions and investments. The model quantifies the impact of these expansions 


\section{ACCEPTED MANUSCRIPT}

on some key performance indicators and on the overall utility and production capacity of the society. We argue that traditional analytical models that work on the premises of stationary behavior and a static response of society to changes in infrastructure do not correctly capture these effects. The land use patterns and spatial expansion computed from the model are validated against existing theory on land use. Preliminary results on how to use the model for value proposition analysis are also presented using simple case studies.

\section{Introduction}

Investment in transportation infrastructure assets has the potential to significantly impact the spatial structure of an economy and produce new socioeconomic opportunities, interactions and behavioral patterns. The long-term value proposition of transportation infrastructure investments therefore can be significantly distorted if the short term effects of spatial externalities on land-use patterns, economic expansion, and migration patterns are not properly included in the analysis. Some of these effects occur over a short period of time and soon after the investment materializes, while others take longer and follow more steady patterns. For instance, some shortterm behavioural changes are expected due to the fact that a better transportation system reduces the commute time of people in the society. As a result they can allocate more time to production and leisure activities. The changes in travel times between different origins and destinations motivate people to change their residence and work locations over the long term. Any public and/or private investment and value proposition model should have a complete understanding of 


\section{ACCEPTED MANUSCRIPT}

these short-term and long-term impacts prior to making the capital investment decision.

In this article we focus on transient impacts and pursue the following objectives:

(1) Develop the necessary constructs of a generic primal model and validate that it is capable of capturing some real effects and interactions in transportation applications. We also demonstrate that traditional static models cannot capture some of these effects.

(2) Illustrate the value proposition; i.e., value to be delivered of a typical transportation infrastructure asset investment.

The model construction is unique and novel in transportation infrastructure investment literature because: (a) It incorporates the fundamentals of urban land markets and the interactions between individuals in the society and their responses to endogenous and exogenous changes in the transportation network. (b) It closes the loop between transportation assets, network flow, and the underlying activities in the society. (c) With the above closed loop, the model is capable of more accurately measuring the net worth of an investment with respect to migrations, business growth, flow changes, and so forth. (d) The proper accounting of the net worth of transportation investments leads to more accurate and formal value proposition models. The model construction is an agent-based framework but we do not use any specific software tool of that kind. Our constructs are generic and are programmed in MATLAB. Appendix A provides a brief description of the programming framework. Computer files are provided as supplemental material.

In our economic system: Individuals try to balance their time between work, which increases their consumption set, and leisure [Varian, 2009]. Individuals interact with the rest of 


\section{ACCEPTED MANUSCRIPT}

the economy in terms of buying or selling products and/or services [Star, 1997]. Personal preferences can vary from one individual to another in terms of leisure or consumption. Depending on the structure of the society and individual's preferences they selfishly or collaboratively attempt to maximize their utility [Samualson, 1938]. Infrastructure investments cause shocks to the economic systems - households and production activity change locations in response to changes in their environment. In real life and in our model, the individuals' behavioral patterns when integrated with shocks due to investments and expansions of transportation assets lead to shifts in population characteristics, land use and traveling patterns, business growth and flows of goods [Makie, 2010].

The dynamic interactions in our framework cannot be captured by traditional deterministic structural equation models of economies which use equilibria based on average or forecasted behaviour and compare a stable baseline case against one or more stable alternatives [17]. Furthermore, many of the traditional models in urban land market find their roots in the mono-centric urban model of W. Alonso [1]. According to Alonso's bid theory, households choose their locations within a certain distance from the Central Business District (CBD) to maximize their utility from the consumption of spatial goods and composite goods under their budget constraints. Fujita and Thisse [12] show that in equilibrium the rent for land is equal to the consumer's willingness to pay for the distance for a given level of utility.

The literature on the Agent-based Computational Economics (ACE) and its use to study aspects of infrastructure investment is quite rich. Several agent-based papers emphasize the importance of social interactions and the effects of spatial externalities on land-use patterns ([17], [6], [13], [21]). Filatova et al. [11], and Parker and Filatova [20] developed an agent-based 


\section{ACCEPTED MANUSCRIPT}

approach to model the micro-scale interactions between buyers and sellers and incorporate feedback of market transactions by focusing on direct modeling of price formation and market transactions as opposed to developing more general models. In these partial, as opposed to general, equilibrium models, agents start with the assumption that their disposable budget for housing is independent of their selected locations. In this article we relax that assumption and let the agents generate their own income by selecting an occupation, place of residence and a place to work. Basu, Pryor and Quint [4] developed an agent-based model of US economy by focusing on the Households, Firms, Banks, Government, Financial Marketplace, Federal Reserve and Realtor and the Capital Goods Produceing agents. That model was used to simulate and test different monetary and economic policies. While their model performed well in simulating the financial and economic interactions, there is no functionality embedded in the model to include spatial analysis that would allow for analysis of economic impacts of infrastructure investments. In their paper, Ehlen and Scholand [8] developed cellular, enterprise structure that allows for detailed understanding of intra-firm, inter-firm and firm-infrastructure dynamics caused by manmade and natural disruptions to electric power, telecommunication and other critical infrastructure. The literature on this subject thus far shows the interdependencies between the economy and the power sector. However it has not yet explored the interdependencies of the spatial structure of the economy and the transportation infrastructure. The National Infrastructure Simulation and Analysis Center (NISAC) Agent-Based Laboratory for Economics' N-ABLE ${ }^{\mathrm{TM}}$ has developed a large scale microeconomic simulation tool that models the complex supplychain, spatial market dynamics, and critical-infrastructure interdependencies of businesses in the 


\section{ACCEPTED MANUSCRIPT}

U.S. economy [19]. N-ABLE ${ }^{\mathrm{TM}}$ is designed to model disruptive events and their impact on US business.

Generally speaking, the current ACE research follows four different objectives: (i) Empirical understanding: "Why have particular global regularities evolved and persisted, despite the absence of centralized planning and control?" [9] and [5]; (ii) Normative understanding: "How can agent-based models be used as laboratories for the analysis of economic policies?" [14] and [16]; (iii) Qualitative insight and theory generation: "How can economic systems be more fully understood through a systematic examination of their potential dynamic behavior under alternatively specified initial conditions?" [2], [3]; and (iv) Methodological advancements: "How best to provide ACE researchers with the methods and tools they need to undertake the rigorous study of economic systems through controlled computational experiments?" [2] and [5]. Our main contribution is on (iv) with regard to the construction of the model and on (ii) for using the model to develop a value proposition analysis framework. Furthermore, our model is capable of capturing queueing effects and complex interactions that cannot be replicated by using simple structural equations.

\section{Technical Approach}

\section{Preliminaries}

The primal society used for illustration in this article consists of: (i) A population of citizens modelled by agents, where each agent is capable of producing only one product at a time but will require more than one product to survive and no production can be stored for future 


\section{ACCEPTED MANUSCRIPT}

consumption; (ii) A central market where all agents exchange their products; (iii) A grid with nodes representing land blocks which can be used for production or residence by agents, and links representing connection between these land blocks. All these nodes are homogenous in terms of their capacity but the level of available resources can change from one node to the other. Node capacity determines the number of agents that can live/work in that node and the level of node resource(s) reflects the level of available resources necessary for Product A and Product B production. Each agent is uniquely identifiable by a set of static characteristics and a set of dynamic properties that change based on the agent's decisions. The agent's static characteristics include its utility and production functions. Agents' dynamic properties include residence location, work location, occupation, working hours (total production), and total consumption.

The economy simulation clock is synchronized with production and distribution cycles of the two products. At the beginning of a given time period, which is assumed to be constant, agents start producing their designated products followed by the distribution of these products to the market place where they also purchase their own product needs. These activities also involve traveling between agents' resident locations and business district(s). It is also assumed that agents have an opportunity for leisure activities within a given period of time. At the end of a time period, the states of the economy and society are updated according to system dynamics, which will be formulated and described shortly. The next time period starts with a new production cycle and with information on agents' residence and work locations and occupations. From a practical point of view, the interpretation of a time unit will be dependent on the problem context and scope, and can range from one day to a month and even longer. For practical reasons, we assume that our time unit is sufficiently long so that time between two clock ticks 


\section{ACCEPTED MANUSCRIPT}

covers all the activities that pertain to production and distribution of products, and leaves time for additional leisure activities and also any changes in agents' residence and occupation. We also assume that investment decisions and the follow up development activities take place within the same time scale as production and distribution activities. We understand that this is an oversimplification of reality, but it is a small price to pay for constructing a simple model that can capture the complex dynamics of land formation and value generation opportunities from transportation investments. One final assumption is that, within one time unit, agents' states, ownership of business and residential locations, or grid (transportation) configuration can change only once.

Each agent has the objective of maximizing its own utility through a set of decisions. Additionally, agents are price takers and only decide on how much of each product they should produce. The market clears by setting prices for Product A and Product B, so that the total quantity produced and consumed of Product A and Product B remain equal at the end of each period. The market sets new prices for Product A and Product B, and brockers the reallocation of Product A and Product B production among the participating agents. It is assumed that the switching costs between the two products are negligible. The consumption and production of Product A and Product B along with the leisure time determine the utility of the agents. At the end of each period, agents pay for their residential and work locations based on their production and utility functions. To simplify the model and to avoid complications of economic closure loops, there will be no actual payment in this model and agents will only announce their willingness to pay for the land. In fact, since the decision of where to live and work automatically cuts into individuals' production and consumption capabilities, the foregone 


\section{ACCEPTED MANUSCRIPT}

consumption or opportunity cost embedded in the model is in essence the rent payment. The production function of an agent identifies the labor effectiveness of the agent in the production process.

Once they pay for their work and residential land, agents compare their own utility to the utility of other agents, and the agents with a utility lower than a certain threshold decide to migrate out of the network (society). With respect to our primal society these migrating agents cease to exist. The migrating agents open up space, which can then be utilized by new agents who are interested in moving into this society. Agents moving in are expected to over-perform (above threshold) in the society and possess characteristics similar to the existing overperforming resident agents. In addition to moving in or out of the system, agents can relocate within the society. The move-ins and relocating agents identify a list of affordable locations and select the best combination of residence location, work location and occupation for the next period. We assume that moving costs are negligible, thus not included in the model. These moves are not regulated and it is assumed that only a certain percentage of population make such moves. More regulations can be imposed on such moves in the model extension.

\section{Problem Formulation}

In this section, we present the mathematical formulation of our primal society and its economics. We start with common nomenclature; additional notations will be defined as formulation develops. 


\section{ACCEPTED MANUSCRIPT}

\section{Nomenclature}

- $t$ : Time period - constant time between two simulation clock ticks,

- $h, b$ : Indices used for Product A and Product B, respectively,

- $a$ : Represents an agent,

- $a_{h}$ Agent producing Product A,

- $a_{b}$ Agent producing Product B,

- $\quad R_{r i j} \in[0,1]:$ Availability of land resources in node $i j$ required for production of $r \in\{h, b\}$

- $\quad L_{i j}$ : Total land in node $i j$.

- $G$ : The Grid

- $w_{\mathrm{a}} \quad$ The total working hours of agent $\boldsymbol{a}$ within a planning period,

- AT: The available time of an agent within a time period.

- $\lambda_{a t}$ : The leisure time of agent $\boldsymbol{a}$ during time period $t$

- $C_{a, r, t}$ : Consumption quantity of $r \in\{h, b\}$ by agent $\boldsymbol{a}$ during time period $t$,

- $P_{a, r, t}:$ Production quantity of $r \in\{h, b\}$ by agent $\boldsymbol{a}$ during time period $t$

\section{Grid Definition}

We model the geographic region of our primal society by a grid $G$, where:

- $G=\left\{N, A, W \mid N=\left(n_{i j} \mid i=1 . . m, j=1 . . n\right)\right.$;

- $A=((i=k \wedge j=l \pm 1) \vee(i=k \pm 1 \wedge j=l) \vee(i=k \pm 1 \wedge j=l \pm 1))$; 


\section{ACCEPTED MANUSCRIPT}

- $W=\left(W_{(i j, k l)} \mid W_{(i j, k l)}=x\right.$ where $(i=k \wedge j=l \pm 1) \vee(i=k \pm 1 \wedge j=$

$l)$ and $W_{(i j, k l)}=\sqrt{y}$ where $\left.(i= \pm k \wedge j=l \pm 1)\right)$.

$\mathrm{N}$ is the set of nodes, $\mathrm{A}$ is the set of links and $\mathrm{W}$ is the weight of the link. Each node in the grid has two types of resource variables, namely $R_{r i j}$ and $L_{i j}$. All links are accessible by all agents (see below for the definition of agents) and can be used for travel between two nodes or locations within the grid. Agents choose to travel on the shortest path or link. The weight of each link defines the travel time on that link. These weights change dynamically according to the link capacity and number of agents that chose to travel on that link. Starting from a base weight, link weights change according to:

- New Link Weight $=$ Base Link Weight, $\quad$ if traffic count $<$ capacity

- New Link Weight $=$ Base Link Weight/EXP(-traffic count/link capacity), if traffic count > capacity

Note that the above calculations are the same for residential ad business travels, thus congestion uniformly impacts the two travel types.

Agents

Each agent in the system is an entity with a unique production and utility function.

\section{Utility Function}

The Cobb-Douglas form [7] is used for the utility function. This is a commonly used utility 


\section{ACCEPTED MANUSCRIPT}

function in economic analysis. The utility of agent $a$ at time period $t$ is calculated by Eq. (1), which relates leisure time and consumption of products A and B to utility:

$$
U_{a t}=\lambda_{a t}^{\alpha_{a, 1}} C_{a, h, t}^{\alpha_{a, 2}} C_{a, b, t}^{\alpha_{a, 3}}
$$

where $\lambda_{a t}$ is the agent's leisure time at the end of time period $t, C_{a, h, t}$ is the agent's Product A consumption, and $C_{a, b, t}$ is the agent's Product B consumption. The coefficients $\alpha_{a, 1}, \alpha_{a, 2}, \alpha_{a, 3}$ are the individual's elasticity of utility with respect to leisure time, consumption of Product A and consumption of Product B. The utility function is linearly homothetic and therefore $\alpha_{a, 1}+\alpha_{a, 2}+\alpha_{a, 3}=1$. Note that this does not restrict the generality of the conclusions in this analysis.

\section{Production Function}

The Cobb-Douglas function is also used to model production capacity. Output of commodity $h$ is the result of application of resource $(R)$ and labor time $(w)$. The agent's production coefficients $p_{a h}$ and $p_{a b}$ represent a combined labor and resource intensity of production processes for Product A and Product B, such that $p_{a h}+p_{a b}=1$. Therefore,

$$
\begin{aligned}
& P_{a, h}=R_{h i \mathrm{j}}^{1-p_{a h}} w_{\mathrm{a}}^{p_{a h}} \\
& P_{a, b}=R_{b i j}^{1-p_{a b}} w_{a}^{p_{a b}}
\end{aligned}
$$




\section{ACCEPTED MANUSCRIPT}

\section{Optimality for Individual Agents}

At each time period the agents in our model have to solve for location and labor time. They have to decide what to produce, where to produce, where to live and how much time to spend on production and leisure. An agent with the residence location of $i j$ and work location $k l$ can maximize its utility by allocating its available time between leisure and production. Each agent makes $n_{r c}$ trips from its resident location to the grid's central location. It also makes $n_{r w}$ trips between work and residence locations. Let $s_{i j k l}$ be the shortest travel time between residence location at node $i j$ and work location at node $k l$. Also let $s_{i j c c}$ be the total travel time between central grid location and agent's residence at node $i j$. The total travel time of the agent within a given period is given by:

$$
T_{i j k l}=2 \times n_{r w} \times s_{i j k l}+2 \times n_{r c} \times s_{i j c c} .
$$

At the beginning of each period the objective of the agent is to allocate the remaining $\left(A T-T_{i j k l}\right)$ hours between work and leisure to maximize its utility. It is assumed that agents need to allocate at least a portion of their available time to leisure. Therefore, the agent's leisure time is given by Eq. (5):

$$
\lambda=24-T_{i j k l}-w_{a}
$$

If agent $a\left(=a_{h}\right)$ starts a period with zero amount of Product $\mathrm{A}$ and Product $\mathrm{B}$, its end of period utility can be calculated by Eq. (6), where he/she sells $\Delta H$ (measured in units or volume) of Product A and $\Delta B$ of Product B. We have 


\section{ACCEPTED MANUSCRIPT}

$$
U_{a t}=\lambda^{\alpha_{1}}\left(P_{a, h}-\Delta H\right)^{\alpha_{2}}(\Delta B)^{\alpha_{3}}
$$

If we substitute $\lambda$ with Eq. (5) and $P_{a, h}$ by Eq. (2), then the utility function of agent $a$ can be rewritten as:

$$
U_{a t}=\left(24-T_{i j k l}-w_{a}\right)^{\alpha_{1}}\left(R_{h k l}^{1-p_{h}} w^{p_{h}}-\Delta H\right)^{\alpha_{2}}(\Delta B)^{\alpha_{3}}
$$

The optimization model for agent $a_{h}$, in terms of Product A is:

$$
\operatorname{Max} U_{a t}=\left(24-T_{i j k l}-w\right)^{\alpha_{1}}\left(R_{h k l}^{1-p_{h}} w^{p_{h}}-\Delta H\right)^{\alpha_{2}}(\Delta B)^{\alpha_{3}}
$$

s.t.

$$
\begin{aligned}
& A T-T_{i j k l}-w \geq 0 \\
& p_{a, h} \times \Delta H-p_{a, b} \times \Delta B=0
\end{aligned}
$$

The first constraint assures that the agent is not working more than its total available time and the second constraint keeps the wealth of the agent constant. Note that there is no monetary flow in the society. For agent $a_{b}$, which produces Product $\mathrm{B}$, the optimization is formulated as:

$$
\operatorname{Max} U_{b t}=\left(24-T_{i j k l}-w\right)^{\alpha_{1}}(\Delta H)^{\alpha_{2}}\left(R_{b k l}^{1-p_{b}} w^{p_{b}}-\Delta B\right)^{\alpha_{3}}
$$

s.t.

$$
\begin{gathered}
A T-T_{i j k l}-w \geq 0 \\
p_{a, h} \times \Delta H-p_{a, b} \times \Delta B=0
\end{gathered}
$$

Each agent in the economy allocates its time between leisure and production based on its estimated future product consumption assuming that it can sell all of its production in the market and buy all of its demand at the current market price. At the end of each period, agents use their available inventory of the product they produce to purchase the other commodity. This process 


\section{ACCEPTED MANUSCRIPT}

sets new prices for the two products and reallocates the total production requirements among agents. The above optimization problem is solved using MATLAB existing solvers.

\section{Market Optimality}

Since neither product can be stored the sum of Product A and Product B for the society stays the same before and after the trade, i.e., $\sum \Delta H=0$ and $\sum \Delta B=0$. The central market clears only when the supply and demand for the two products are equal at market price. At the end of the clearing process each agent consumes its available inventory of the two products and ends the period with a utility based on the level of its consumption and leisure.

The central market functions according to the following policy:

(1) The central market sets the relative price $k$ of Product $\mathrm{A}$ and Product B such that $\Delta H=$ $k \Delta B$

(2) Agents who produce products announce their supply and demand for Product A at market relative price of $k$;

(3) Each $a_{h}$ maximize its utility by solving:

(a) $\max _{\Delta H} \lambda^{\alpha_{a_{h} 1}}\left(H_{o a_{h}}-\Delta H_{a_{h}}\right)^{\alpha_{a_{h}}}\left(k \Delta H_{a_{h}}\right)^{\alpha_{a_{h} 3}}$

(4) Each $a_{b}$ maximize its utility by solving:

(a) $\left.\max _{\Delta B} \lambda^{\alpha_{b_{h} 1}(1 / k} \Delta B_{b_{h}}\right)^{\alpha_{b_{h} 2}}\left(B_{o b_{h}}-\Delta B_{b_{h}}\right)^{\alpha_{b_{h} 3}}$

(5) If $\sum 1 / k \Delta B_{b_{h}}=\sum \Delta H_{a_{h}}$ set $k$ as the new market price, otherwise if $\sum 1 / k \Delta B_{b_{h}}>$ $\sum \Delta H_{a_{h}}$ increase $k$, else decrease $k$ and go back to step 2 . 


\section{ACCEPTED MANUSCRIPT}

Rent

An agent's willingness to pay for its residential and work locations is calculated based on its end of period utility and production values. According to Varian [26], an individual's willingness to pay for spatial goods (or land) is a function of its utility, income and price of other goods in the market, so that the increase in the utility increases the willingness and the increase in the price of other goods decreases the willingness. It is assumed that agents have a higher willingness to pay for a unit of residential location than a unit of work location; this assumption reflects agents' higher perceived utility for residence compared to work in this agrarian society. This assumption is an indirect derivative of the von Thunen theory which states: "the user of an activity (land use) associated with high value products can bid higher land rents and, thus, outbids other users that cannot pay the same rent." [1]

The price of each node is calculated as the sum of the willingness to pay over all agents who are planning to use that node as their residence and/or work location. Eq. (8) shows a simplified representation of willingness to pay based on Varian [26]. This equation adheres to our model's data availability and shows similar characteristics without getting into complexities of calculating the price of aggregate goods in the simulated society.

$$
\text { residential }=\left(p_{a, h} \times H+p_{a, b} \times B\right) / 3 e^{1-u t i l i t y}, \text { work }=\left(p_{a, h} \times H+p_{a, b} \times B\right) / 4 e^{1-u t i l i t y}
$$

\section{Migration and Relocation}

At the end of each period certain changes can occur in the population structure of the society; agents can move in, move out or move within the society's geographical bounds. The following 


\section{ACCEPTED MANUSCRIPT}

logic describes these changes:

- Agents indirectly compare their utility to the utility of other agents in the society (by comparing the basket of goods and leisure time they have with that of other agents and assuming that their utility functions are similar) and decide to leave if they under-perform with respect to a certain utility threshold. The empty spots are then filled by new incoming agents with static characteristics similar to the existing over-performing agents (agents with utility higher than a certain threshold). In addition to move-ins and moveouts a portion of agents can change their occupation, work and residence locations within the society. This portion is a variable in the model.

- Every agent (with move-in plans) reviews all the nodes in the grid, retrieves the occupancy price associated with that location for work and residence and creates a list of options. It then selects an option which maximizes its future utility.

- The heuristic approach to maximization works as follow. Our agent selects the most affordable location closest to the central grid location for its residence and selects the best affordable work location based on its resource availability and proximity to its residence location. Once these locations are selected the agent chooses its new occupation by solving the time allocation problem for $\mathrm{A}$ and $\mathrm{B}$ productions from these locations and selects the set with the higher future expected utility.

- If there is enough available space in the destination node (determined by the optimality condition) for work/residence the agent moves to that node. If there is not enough space available at the destination node, one of the following scenarios can happen depending on the type of move and land use at the target location: 


\section{ACCEPTED MANUSCRIPT}

- Agent is seeking residence at an exclusive residential location - In this case the current resident with the lowest utility will be evicted from the target location and the new agent will occupy its space. The evicted agent will select a new residential location before the start of the next period.

$\circ$ Agent is seeking residence at a mixed residence and work location - Residential agents take priority over work agents. In this case a work space will be taken away from its current occupier and the space will be allocated to the new incoming agent.

$\circ$ Agent is seeking a new work location - If the agent seeking work location can afford the whole block of land, all agents currently using the target location will be evicted and the new agent will occupy the location for work. All evicted agents will select new locations before the start of the next period.

We note that agents change their residents/work locations either willingly (according to a $\%$ defined in the model) or by eviction due to the reasons outlined above.

\section{Model Calibration}

The model can be calibrated to include basic production activities such as farming or more sophisticated activities such as manufacturing. The US Department of Census categorization of industries can be used to create different classes of agents and the Input / Output tables from the Bureau of Economic Analysis can be used to connect consumption of resources to production of different products. The extension of the primal model to real applications requires quantification and calculation of marginal utility curves for the member agents of the society and introduction 


\section{ACCEPTED MANUSCRIPT}

of land use for upstream (such as farming and manufacturing) and downstream (such as retail and entertainment) activities. Parry and Small [22] compute transport asset utility as a function of travel cost, travel time, waiting times, congestion, and service frequency of public transport. This becomes the basis to drive demand curves for transport infrastructure assets. Sagerer and Wills-Johnson [23] use this model to compute consumer surplus resulting from infrastructure asset investments. Borrowing ideas from these earlier works and using the America Time Use survey data from the US Department of Labor we can compute marginal utility functions for our agents.

\section{Validation and Experimentation}

We carry out validation of the model through behavioral patterns that develop in the society when some important driving factors change. For example, we focus more on how land shapes form and shift and less in their sizes and amounts. We are more interested in interactions and values that are generated as a result of investments on a network link. Our model is not intended for quantitative prediction of any sort. Furthermore, we want to show that the model constructs developed here closely capture the impact of transportation infrastructure investments on some select response measures or key performance indicators (KPI). The bases for comparison will be some known theoretical results or behavior observed in real life case studies. In all cases, the comparison will be made in abstract terms with no exact numerical evaluations.

\section{Validation of Spatial Formation}

As a base case we consider a society of 100 agents living in a $20 \times 20$ grid where the central 


\section{ACCEPTED MANUSCRIPT}

location is located over node $(10,10)$ and Product A and Product B production resources are uniformly distributed at their maximum level of one. Agents are initially assigned random residence and work locations. As shown in Figure 1, the initial distribution of work and residence locations do not follow any specific pattern, where $x$ and $y$ axes are the location of the node on the grid and $z$ axis is the number of agents in that location.

Agents are allowed to change their locations to maximize their utility, e.g., reduce the total travel time and allocate the released time to more valuable (in utility terms) activities. This maximization effort impacts the spatial structure of the society leading to population concentration close to the central grid location. As shown in Figure 2, agents select the area immediately around the central grid location for residential usage to save on travel time, where $x$ and $y$ axes are the location of the node on the grid and $z$ axis is the number of agents in that location. Recall that agents are generally willing to pay more for a land unit of residence than for work location. This makes the inner "circle" unaffordable for production of Product A and Product B and pushes it to the outside of the inner residential circle.

This spatial shape of the society is in line with the mathematical closed form results for "rent theory" following the mono-centric urban model developed by Alonso [1] that applied and refined von Thunen's original ideas. The rent gradient of this society is similar to Alonso's hypothetical rent gradients as shown in Figure 3, where the activities with the largest amount of output per acre are located closest to the central business district. Deeper examination of the model shows that agents with higher production and utility locate themselves in locations closer to the central business district. Our approach generates spatial and residence patterns that closely resemble Alonso's model: 


\section{ACCEPTED MANUSCRIPT}

\section{Sensitivity Analysis of Key Performance Indicators (KPI)}

Our model validation continues and this time we focus on some transportation related KPIs. We show that the primal model is capable of appropriately capturing transient and in equilibrium changes in these KPIs as relocations and job changes occur. Our intention here is not to claim that these effects are similar or even close to real life scenarios, as the latter ones are too complex to describe. We would prefer to verify that change patterns are reasonably appropriate within the transportation context.

We start with travel times. For the illustrative example, agents are initially distributed in a random manner, which lead to inefficient travel time KPI due to long travel times between work and their residence and from there to the central location. But as these agents relocate to maximize their utility, the total travel time reduces to a steady value. As the average utility of agents in the society increases, some agents tend to maximize faster than others, and the gap between slow-reacting agents and fast-reacting agents widens. With this gap growing the location desirability becomes less attractive to the slow acting agents. In this specific example, the steady state travel time, as show in Figure 4, is less than one third of the travel time compared to the starting period.

There are a number of other societal key performance indicators included in our study, namely, distance travelled and average travel speed. These KPIs show a goal seeking behavior resulting from the equilibrium reached due to interaction of agents. However this equilibrium is not reached instantaneously and when it is reached it is not maintained at a constant level and major KPIs vary around their long term mean. 


\section{ACCEPTED MANUSCRIPT}

The total Travel time of agents is a function of their average speed (which depends on congestion and speed limit) and the total distance travelled. Note that the travel time (and the speed) over a link depends on the weight factor of that link which dynamically changes with the number of agents travelling over the same link. Figure 5 shows the change in the distance travelled and the average speed. With more population density, average distance travelled by each individual reduces and this in turn leads to the increase in roadway congestion and reduction in the average speed of travel.

The distribution of population over the grid, total production and prices of Product A and Product B are three closely related characteristics of the society. For the example problem, agents have higher willingness to pay for Product A due to its higher weight in their utility functions. This, in turn, leads to higher steady state prices of Product A compared to Product B. The increase in the price of Product A makes the production of Product A more attractive and more agents start selecting Product A production as their primary occupation (see Figure 6).

The change in the occupation and in-and-out migration of agents lead to steady levels of Product A and Product B production as shown in Figure 7. The relative importance of Product A in the utility function of an agent leads it to have a larger share of the total production.

One of the important spatial characteristics of the grid affected by agents' decisions is the price of land (total willingness to pay for each node). In the relocation process, agents compete to acquire land that maximizes their utility based on their willingness to pay. This competition leads to increases in prices in locations with higher resource availability or desirability for residence. At the beginning of the simulation, agents are randomly scattered around the grid, and their willingness to pay for their residence and work location is low and does not follow a 


\section{ACCEPTED MANUSCRIPT}

specific pattern, as can be seen in Figure 8, where $x$ and $y$ axes are the location of the node on the grid and $z$ axis is the sum willingness to pay of agents in that location.

As the society evolves, agents relocate and land prices increase in more desirable locations and with higher access to resources. As mentioned earlier, locations close to the center of the grid are more desirable; therefore, agents are willing to pay higher prices for these locations. Figure 9.b shows the increase in the agents' willingness to pay over time and Figure 9.a shows the total willingness to pay for each node where $x$ and $y$ axes are the location of the node on the grid. The total willingness of a node is obtained by summing over individual willingness of agents within that node.

\section{Impact of infrastructure loss}

The production shift and relocations phenomena can be observed in real life when a major transportation asset (or network of assets) becomes unavailable. This impacts the ability of production centers to transport their cargo to export gateways. The US grain production is mainly concentrated in the central USA. However, the main export gateways are located at Pacific and Gulf coasts. Prior to 1997, Gulf ports had the dominant share of the US grain export. The lack of proper investment in maintenance of the Mississippi water route led to a loss of capacity of the river for transporting the agricultural products from central production locations

to the southern export gateway. During the same period, increased containerization of grain and improvement to the Rail Roads serving Pacific ports turned Pacific ports into attractive gateways for grain export. As the result of these changes the share of Columbia River ports have increased from $16.8 \%$ of total export to $20.4 \%$ based on USDA data adjusted for interior ports [10]. 


\section{ACCEPTED MANUSCRIPT}

The change in the export ports was not the only impact due to the change in the grain export infrastructure. The location of the grain production was also shifted due to the change in the export infrastructure. Simple comparison between intensity of 1997 and 2012 crops production, based on US Census of Agriculture Data, shows that the intensity of production has shifted from central south to northwest (see Figure 10). In 15 years, the production became less intense in the lower part of Mississippi and became more intense in central and west of Illinois, Nebraska and North Dakota.

\section{Value Proposition \& Optimization}

In this section we use the primal model to develop a value proposition and optimization framework for investment in transportation infrastructure assets. For demonstration, we will use a simple example of investment on a new transportation corridor and will attempt to estimate its socioeconomic value using quantifiable measures. We will show that the primal model is able to capture value creation through improvements in transportation KPIs and the direct impacts of these on production capacity of the society, quality of life and eventually the utility function of individuals. The changes in spatial shape of the society will also be measured. The change in spatial shape of a community directly impacts land use patterns, which, in turn, can lead to adverse environmental impacts and undermine sustainability goals of that community. Finally, we will use the concept of total utility of community or society to optimize the investment size.

\section{Value creation by Improvements in Transportation KPIs}

Suppose that in our illustrative grid example, we plan to invest on a corridor from node $(10,1)$ to 


\section{ACCEPTED MANUSCRIPT}

node $(10,20)$ in order to reduce travel times. The change in travel time from $(10,1)$ to $(10,20)$ is given by:

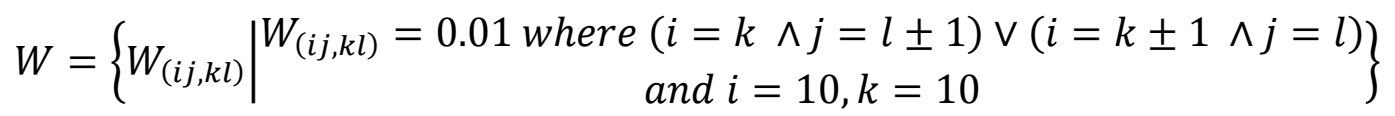

Members of the society will react to this improvement by changing their occupation, work or residence location as well as their time allocations to work and leisure. The new corridor will make it faster to travel across the grid. This reduction in travel time will affect the shape of residential and work clusters by stretching them in the corridor's direction as shown in Figure 11. The first five immediate nodes in each direction (on the corridor) become more appealing for residential use compared to the immediate neighboring nodes not located on the corridor. As the residence locations of agents spreads along the highway, agents relocate their work locations to keep the combination of work/residence location optimal or close to optimal as can be seen in Figure 11, where $x$ and $y$ axes show the location of agents.

As shown in Figure 12, the relocation will reduce the total time spent on the road and consequently increase agents' available time by reducing their drive time, which can later be allocated to different activities to increase their utility.

As shown in Figure 13 the new corridor will increase the total commute distance (13.a) but will increase (due to less congestion) average speed (13.b), the total travel time will settle to a lower value.

This decrease in the total travel time will increase the available time of an agent, which will be allocated to production and leisure activities. This increase in the production will cause an increase in the agents' consumption. These factors, combined with increase in agents' leisure time will lead to an increase to agent's utility. The construction of the new highway will lead to 


\section{ACCEPTED MANUSCRIPT}

an increase in the total production/consumption of Product A and Product B. Figure 14 shows about $10 \%$ increase in production of Product A and Product B due to the construction of the new highway.

In addition to the spatial shape of the society agents' relocation and change in their utility will also impact the land price. The higher desirability of locations along the corridor will increase the price of land along the corridor. In addition to having higher consumption power due to increase in the production, agents are willing to pay a bigger share of their production. Furthermore, higher utility for agents will increase their willingness to pay and will consequently increase the total land price in the network as shown in Figure 15.

\section{Value Optimization of Infrastructure Investment}

We suggest building a response surface to optimize infrastructure investments decisions. For demonstration purposes, consider the illustrative example and investment on the new corridor $\{(10,1)-(10,20)\}$. To create a response surface model we incrementally compute the value of investment on the corridor, starting from $\{(10,9)-(10,11)\}$. Each increment is then expanded from both sides until the final size is reached. At each step, the socioeconomic value of the newly expanded corridor is measured and plotted as the response surface as shown in Figure 16.

The response lines in Figure 16 show the diminishing effect of corridor expansion on the utility improvement and production function. For this example, the reduction in traffic congestion in the central residential area has the highest impact on improving the utility and production. The magnitude of the improvement reduces as the corridor expands to $(10,1)$ and $(10,20)$. 


\section{ACCEPTED MANUSCRIPT}

\section{Extensions to More Complex Societies}

The Classical model of Alonso describes the steady state of a mono-centric society with uniform availability of resources for production and transportation. The above framework can relax this assumption and look at multi-centric societies, and societies with non-uniform distribution of resources or the transitional state of the society. The following examples demonstrate how this framework can be used for modeling more complex scenarios.

\section{Mono Centric Society with Non-uniform availability of resources:}

By relaxing the resource uniformity assumption we can model the impact of infrastructure availability on more complex scenarios. Figure 17 below shows a case of non-uniform resource availability for Product A and Product B. The land resource used for Product A has bell shaped distribution with two centers at $(12,2)$ and $(14,17)$ locations with (Figure 17a) and the land resource used for Product B has a bell shaped distribution centered at $(3,4)$ (Figure 17b). The central business district of the society is kept in its original location.

The difference in resource availability leads to the emergence of different agent behavior in terms of their selection of work and residence. Figure 18 below shows how the residence area and productions areas for Product $\mathrm{A}$ and Product $\mathrm{B}$ emerge in response to the non-uniform availability of production resources. In the original case study where resources were available uniformly, agents use the area immediate beyond the inner circle for the production use (Figure 2b). However the non-uniform availability of the resources disrupts that pattern and generates a society with a different spatial shape. 


\section{ACCEPTED MANUSCRIPT}

The proposed model is also capable of capturing the societal changes caused by the changes in underlying infrastructure. Suppose at time period 100 the connectivity between central business location and the center resource required for Product B is improved. Such a change, as shown in Figure 19, will lead to a change in spatial shape of the society. However this change is not as significant as the change in the uniform resource availability case.

The difference in settlement patterns leads to different levels of societal metrics. While both societies are initially populated with the same set of agents, the higher and more uniform availability of resources leads to higher societal utility in the uniform case compared to the nonuniform case. This is shown in Figure 20.

We note that infrastructure improvements produce significantly different impacts under uniform and non-uniform resource availability conditions for the two classes of productions, as shown in Figure 21.

In addition to relaxing the assumptions on uniform resource availability we can use this framework to relax the mono-centric assumption and compare the impact of infrastructure improvements in the presence of competing societies. Figure 22 below shows the steady state for a case of two neighboring societies under the assumption of uniform availability of resources.

Through creation of a multi-centric society the new framework will have the ability to compare the impact of infrastructure investments on societies as a whole through the change in behavior of individual agents. An improvement in the transportation connectivity of the grid from $(0,10)$ to $(20,10)$ will make the society centered at $(10,10)$ compared to the society centered at $(10,30)$, and agents will migrate from the less appealing society to the more appealing one. This migration is shown in Figure 23. 


\section{ACCEPTED MANUSCRIPT}

This migration will lead to changes in the population and land use, as shown in figure 24, as well as the production and utility of the societies which couldn't be captured through the classical frameworks.

\section{Discussion \& Conclusion}

In this article we developed Agent-Based Computational Economics model constructs for a primal society. Through a number of examples, we showed that the model is capable of capturing some important impacts of transportation infrastructure investments. To the best of our knowledge this is the first application of agent based computational economics to transportation planning. The model focuses on land use patterns and the spatial shape of the society. It further calculates the impacts of transportation infrastructure changes on some key performance indicators. This dynamic model closes the loop between infrastructure changes and societal response measures, including key performance indicators over time and in equilibrium. It gives regional and local planners an additional tool to quantify the economic and socioeconomic impacts of large investment projects in short-term and long-term periods. Our model is a good alternative to the standard Four-Step highway traffic model $[18]$ because that model does not include the feedback effects that our model does. Furthermore, our model allows for one to develop an integrated cost-benefit and economic impact analysis that would improve transportation infrastructure decision-making. With suitable development and refinement of the model for specific transportation infrastructure investment decisions, regional planners and engineers may acquire better insight into the dynamics of the changes in costs and benefits over a project's life cycle. 


\section{ACCEPTED MANUSCRIPT}

Incremental impact of an investment is also measurable as shown in Figure 16. Incremental impact analysis will indeed allow planners and investors to value their investment strategy over time and establish the diminishing effects of it, so as to maximize the return of investment. We presented a few examples on how to use the model for value proposition on the basis of the key performance indicators, utility function and societal production capabilities. We believe this is an area that requires much additional work and further extension of the model. Model calibration using real data and incorporating industrial structure as described in InputOutput tables will also make this model more tractable for real case studies. Future research should also include the time and distance sensitivity of relocation costs. It has long been observed that people often do not move from high unemployment areas to low unemployment areas of a country, largely due to their family and friend networks. We should also allow for highway construction to be done over time so that we can measure the effect of disruption on economic activity. This is a particularly important element in the decision of when and how to retrofit infrastructure such as bridges.

\section{Supplemental Material}

Supplemental data for this article can be accessed on the publisher's website.

MATLAB® Functions used in Towards Closing the Loop Between Infrastructure Investments and Societal and Economic Impacts

\section{Summary}




\section{ACCEPTED MANUSCRIPT}

This document presents a brief description of the MATLAB ${ }^{\circledR}$ program used for modeling the impact of infrastructure changes in the social and economic structure of a primal society. The program folder contains scripts, functions, and a data file that includes assigned values to arguments used by functions and scripts. It is assumed that potential users are familiar with structure and language of MATLAB program.

\section{Scripts}

The scripts execute a series of MATLAB statements and functions. They are intended to provide quick access to the functionality of the program. Scripts are organized in two different folders: OneEconomy and TwoEconomies. Each folder contains functions and scripts to run the simulation and generate the graph the associated graphs.

- OneEconomy

- mainUniform.m is the simulation model for figures: $1,2,4,5,6,7,8,9,11,12$, 13, 14 and 15;

○ mainNonUniform.m is the simulation model for figures: 18, 19, 20 and 21;

○ graphUniform.m and graphNonUniform.m use the output from mainUniform.m and mainNonUniform.m runs to generate the figures;

- desktopUniform.mat and desktopNonUniform.mat contain all of the output from mainUniform.m and mainNonUniofor.m

- TwoEconomies

○ mainTwoEconomies.m is the simulation model for figures 22, 23, and 24; 


\title{
ACCEPTED MANUSCRIPT
}

- graphTwoEconomies.m uses the output from the mainTwoEconomies. $m$ run to generate the figures.

- desktopTwoEconomies.mat contains the output from mainTwoEconomies.m

\begin{abstract}
Functions
The functions in the program folders accept input and output. mainUniform.m, mainNonUniform.m and mainTwoEconomies.m are the center pieces of the functions in the program folders. These functions run the simulation environments in which the land (grid) and the agents exist and interact. Once these functions are called, they call other functions, assign input values and use their outputs
\end{abstract}

The table below presents the functions in the program folder and their output arguments. 


\section{ACCEPTED MANUSCRIPT}

Function
Output variable(s) and description

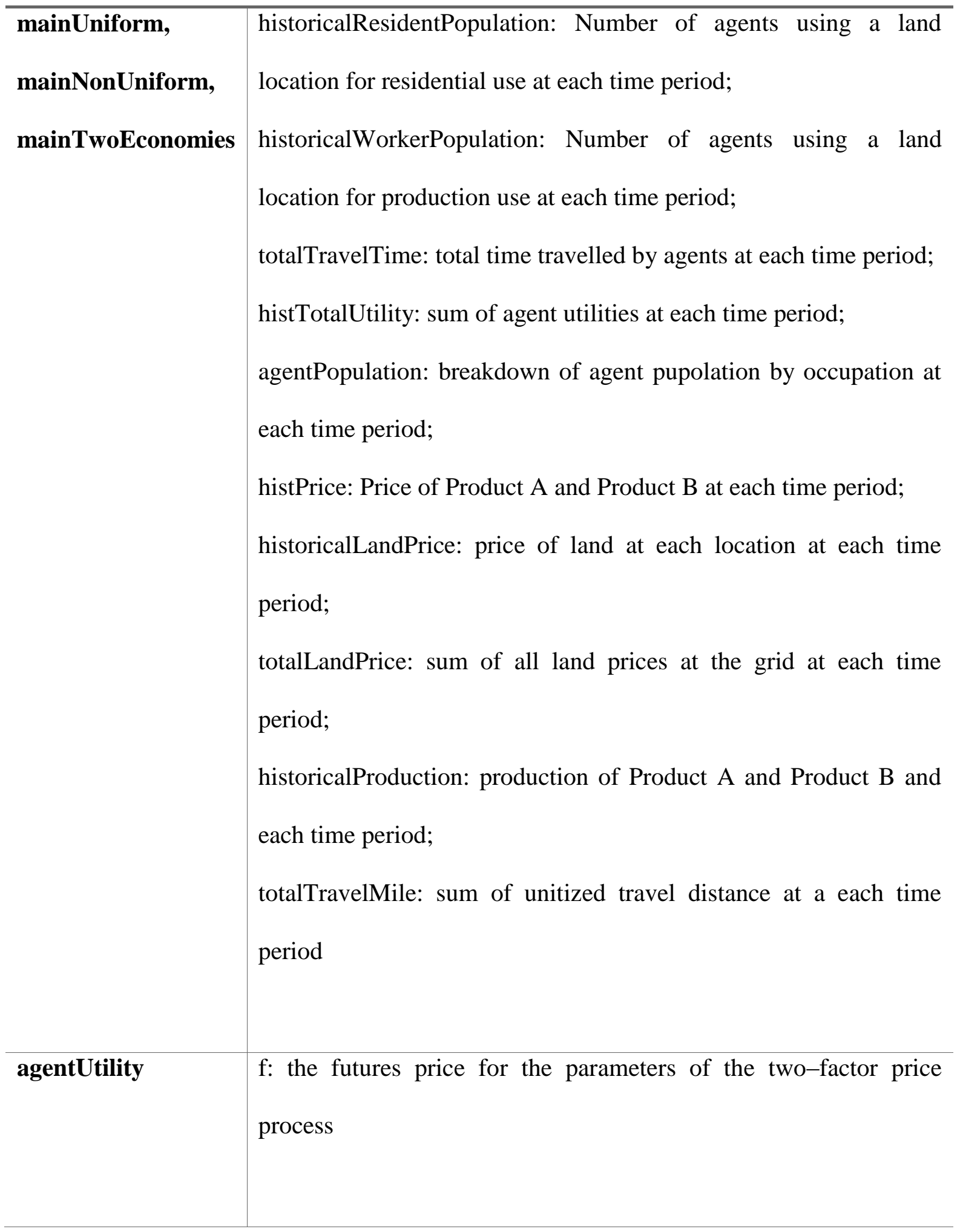




\section{ACCEPTED MANUSCRIPT}

agentConstraints c: inequality constraint to ensure total work and travel hours are less than available time to the agent;

ceq: equality constraint to ensure agent's perceived consumption is equal to its perceived production 


\section{ACCEPTED MANUSCRIPT}

\section{Classes}

Two main classes of objects are used in this program. userAgent and gridLand:

- userAgent: This class identifies all of the agents living and interacting in the society and their characteristics;

- gridLand: This class identifies the characteristics of all of the nodes in the grid;

Class

Methods

\begin{tabular}{l|l}
\hline userAgent & $\begin{array}{l}\text { userAgent: initiate agent; } \\
\text { workPayment: Agent's willingness to pay for residence; } \\
\text { homePayment: Agent's willingness to pay for production locations }\end{array}$ \\
\hline gridLand & $\begin{array}{l}\text { gridLand: initiate the node } \\
\text { addAgent: add an agent to current resident or working agents on } \\
\text { the node; } \\
\text { clearMove: clear the in/out move to the node; } \\
\text { removeAgent: remove a resident or working agent from the block } \\
\text { availableLand: calculate the available unoccupied land in the block } \\
\text { commercialLandPrice: flag to prevent new moves } \\
\text { landPrice: total value of land in the node } \\
\text { movingAgent: agents who are pushed out of the node as the result } \\
\text { of new agents moving in }\end{array}$ \\
\hline
\end{tabular}




\section{ACCEPTED MANUSCRIPT}

Ali Z. Rezvani is a Senior Consultant with the Moffatt \& Nichol's Commercial Services Group, which provides economic and financial analysis and support as input to business development decisions under consideration by local, regional, and international clients. Dr. Rezvani has provided cost-benefit, economic impact, and competitive analysis models that analyze existing markets, commodities, freight movement conditions, and governmental policies as a means of forecasting proposed project impacts on future market and cargo conditions as well as project financial performance. His work has involved transportation infrastructure research and is driven by determining operational and inventory costs of freight across different transportation modes. He has applied this research and modeling focus across a range of transportation projects involving analysis, performance, and forecasting for regional, national, and international cargo movement. Typical transportation projects have involved inland and international transportation systems including multimodal, railroad, and vessel transportation.

Dr. Walter Kemmsies is Moffatt \& Nichol's Chief Economist where he directs market studies, financial analyses and global trade forecasts for projects ranging from strategic development plans for ports through M\&A transactions. He is an advisor to executives at various port authorities and major transportation and manufacturing companies. His professional experience working in Europe, Latin America and Asia uniquely qualifies him as a global economist. More recently he has been focusing on infrastructure investment policies. Prior to joining Moffatt \& Nichol, he was the Head of European Strategy at JP Morgan in London and the Head of Global Strategy at UBS in Zurich. He contributes to the Federal Reserve's Survey of Professional 


\section{ACCEPTED MANUSCRIPT}

Forecasters, is a member of the Industrial and System Engineering department's advisory board at Rutgers University, publishes a regular outlook column in American Shipper, and has been a keynote speaker at major industry and public sector conferences.

Ajith Kumar Parlikad is a University Senior Lecturer at Cambridge University Engineering Department. He holds a PhD degree in Manufacturing Engineering from Cambridge University. His research focus is in examining how asset information can be used to improve asset performance through effective decision-making. He is a member of The Institution of Engineering and Technology (IET) Technical Professional Network Committee on Asset Management and is also a member of the IFAC Working Group on "Advanced Maintenance Engineering, Services and Technology".

Mohsen A. Jafari is a Professor and Chairman of Industrial and Systems Engineering, School of Engineering, Rutgers, The State University of New Jersey, and a Principal at the Rutgers Center for Advanced Infrastructure and Transportation (CAIT), where he oversees the Transportation Safety Resource Center (TSRC), Information Management Group and the newly established Laboratory for Energy Smart Systems (LESS). Since 2006, Professor Jafari’s research focus has been on control and optimization of energy systems with applications in Distributed Energy Resources (DER), microgrids, smart grid and Demand Side Management (DSM). Professor Jafari has been active in research concerning transportation safety since 2005 . He is a member of IEEE and was recipient of the IEEE excellence award in service and research, SAP curriculum award and two Transportation safety awards. He has authored and co-authored over seventy refereed publications and has presented over a 100 invited or contributed presentations around 


\section{ACCEPTED MANUSCRIPT}

the world. Professor Jafari has been a consultant to several fortune 500 companies, and national and international government agencies.

\section{References}

1. Alonso, W. (1964) Location and Land Use, Cambridge, MA: Harvard University Press.

2. Arthur, W.B. (2006) Out-of-equilibrium Economics and Agent-based Modeling, in Handbook of Computational Economics, Volume 2: Agent-Based Computational Economics, NorthHolland.

3. Axelrod, R. (2006) Agent-based Modeling as a Bridge Between Disciplines, in Handbook of Computational Economics, Volume 2: Agent-Based Computational Economics, North-Holland.

4. Basu, N., Pryor, R. and Quint, T. (1998) ASPEN: A microsimulation model of the economy. Computational Economics, vol. 12, no. 3, pp. 223-241.

5. Brenner, T. (2006) Agent Learning Representation: Advice on Modelling Economic Learning, in Handbook of Computational Economics, Volume 2: Agent-Based Computational Economics, North-Holland.

6. Brock, W.A. and Durlauf, S.N. (2005) Social interactions and macroeconomics, vol. 28.

7. Douglas, P.H. (1976) The Cobb-Douglas Production Function Once Again: Its History, Its Testing, and Some New Empirical Values. Journal of Political Economy, vol. 84, no. 5, pp. 903916.

8. Ehlen, M.A. and Scholand, A.J. (2005) Modeling interdependencies between power and economic sectors using the N-ABLE ${ }^{\mathrm{TM}}$ agent-based model, 2842-2846.

9. Epstein, J.M. and Axtell, R.L. (1996) Growing Artificial Societies: Social Science from the Botom Up, The MIT Press.

10. Federal Grain Inspection Services Yearly Export Grain Totals, [Online], Available at http://www.gipsa.usda.gov/fgis/exportgrain/ [August 2014].

11. Filatova, T., Parker, D.C. and van der Veen, A. (2007) Agent-Based Land Markets: Heterogeneous Agents, Land Prices and Urban Land Use Change. Toulouse, France.

12. Fujita, M. and Thisse, J.F. (2002) Economics of agglomeration: Cities, industrial location and regional growth, Cambridge University Press.

13. Irwin, E.G. and Bockstael, N.E. (2002) Interacting Agents, Spatial Externalities and the 


\section{ACCEPTED MANUSCRIPT}

Evolution of Residential Land Use Patterns. Journal of Economic Geography, vol. 2, no. 1, pp. 31-54.

14. Janssen, M.A. and Ostrom, E. (2006) Governing Social-ecological Systems, in Handbook of Computational Economics, Volume 2: Agent-Based Computational Economics, North-Holland.

15. Mackie, P. (2010) Cost-Benefit Analysis in Transport: A UK Perspective. International Transport Forum.

16. Mackie-Mason, J.K. and Wellman, M. (2006) Automated Markets and Trading Agents, in Handbook of Computational Economics, Volume 2: Agent-Based Computational Economics, North-Holland.

17. Manski, C.F. (2000) Economic analysis of social interactions. The Journal of Economic Perspectives, vol. 14, no. 3, pp. 115-136.

18. McNally, M.G. (2007) The Four Step Model, in Handbook of Transport Modeling, $2^{\text {nd }}$ edition, Pergamon.

19. NISAC Agent-Based Laboratory for Economics (N-ABLE TM), [Online], Available at http://www.sandia.gov/nisac/capabilities/nisac-agent-based-laboratory-for-economics-n-able/

[August 2014].

20. Parker, D. and Filatova, T. (2008) A theoretical design for a bilateral agent-based land market with heterogeneous economic agents. Computers, Environment, and Urban Systems, vol. 32, pp. 454-463.

21. Parker, D.C. and Meretsky, V. (2004) Measuring pattern outcomes in an agent-based model of edge-effect externalities using spatial metrics. Agriculture, Ecosystems \& Environment, vol. 101, no. (2-3), pp. 233-250.

22. Parry, I. and Small, K.A. (2007) Should Urban Transit Subsidies Be Reduced?, vol. 99, no. 3, pp. 700-724.

23. Sagerer, S. and Wills-Johnson, N. (2011) A New Approach to Calculating the Benefits Associated with Infrastructure Investment.

24. Samuelson, P.A. (1938) A Note on the Pure Theory of Consumer's Behaviour. Economica, vol. 5 , no. 17 , pp. $61-71$.

25. Starr, R.M. (1997) General Equilibrium Theory: An Introduction, $1^{\text {st }}$ edition, Cambridge University Press.

26. Varian, H.R. (1992) Microeconomic Analysis, $3^{\text {rd }}$ edition, New York: Norton, W. W. \& Company, Inc.

27. Varian, H.R. (2009) Intermediate Microeconomics: A Modern Approach, $8^{\text {th }}$ edition, Norton, W. W. \& Company, Inc.

28. Wikipedia: Johann Heinrich von Thünen. Image: "von Thünen circles city" by Erin Silversmith. Based on the description on the Wikipedia article on von Thünen and Human Geography: Culture, Society, and Space by H.J. de Blij and B. Murphy (7th edition, 2003). Licensed under Public Domain via Wikimedia Commons. https://en.wikipedia.org/wiki/Johann_Heinrich_von_Thünen (accessed 18 July 2015) 


\section{ACCEPTED MANUSCRIPT}
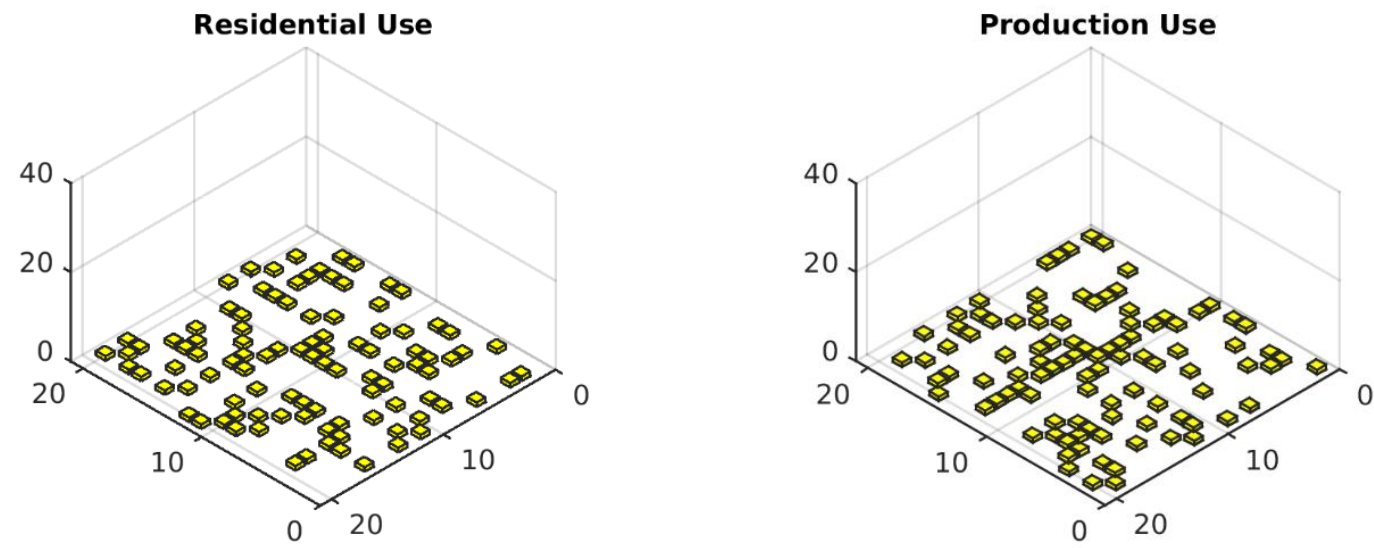

Figure 1: Initial distribution of work and residence locations over the grid $-\mathrm{z}$ axis shows the number of residents in a given grid location

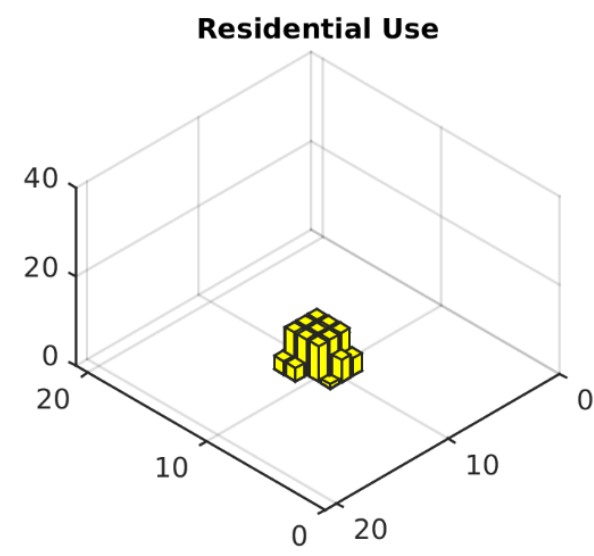

Residence Use (a)

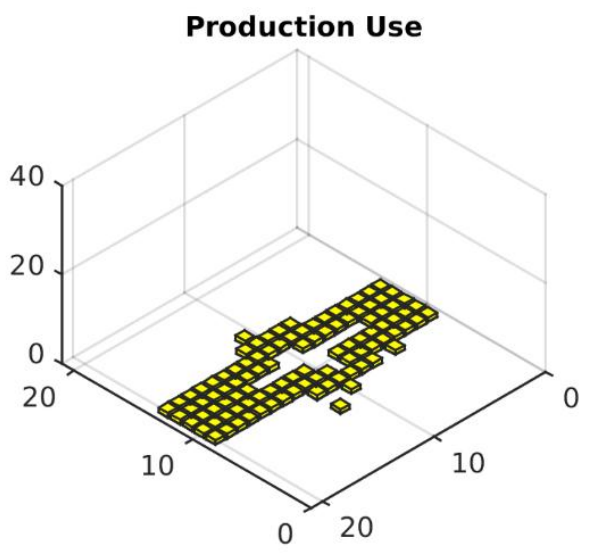

Production Use (b)

Figure 2: (a) Spatial residence patterns over the grid, (b) Spatial work patterns over the grid 


\section{ACCEPTED MANUSCRIPT}

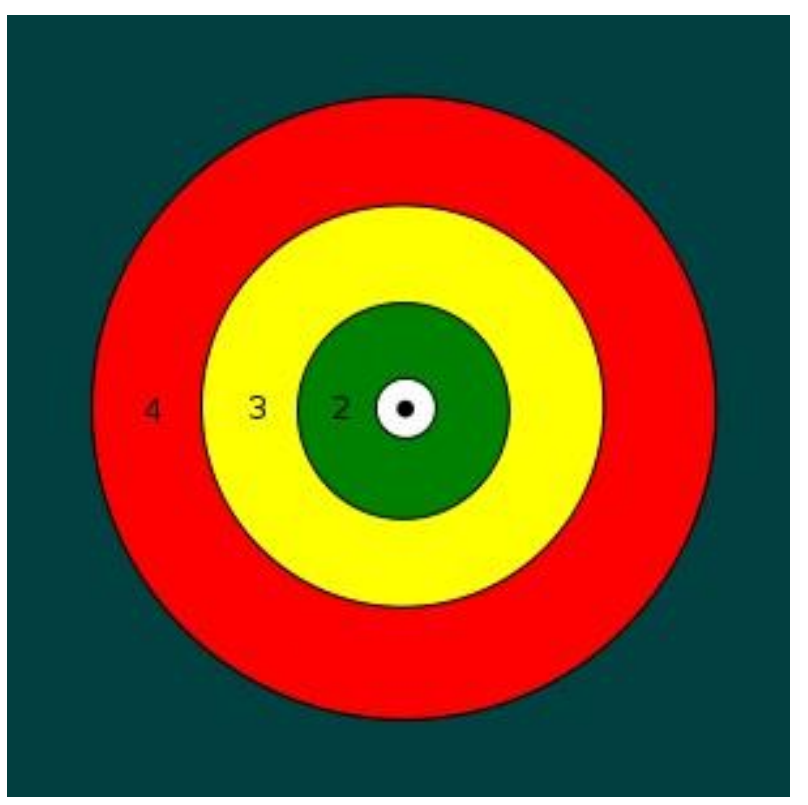

Figure 3: von Thünen's Circles: the black dot represents a city; 1 (white) dairy and marketing gardening; 2 forest for fuel; 3 grains and field crops; 4 ranching; beyond 4, wilderness. Source:

[28]

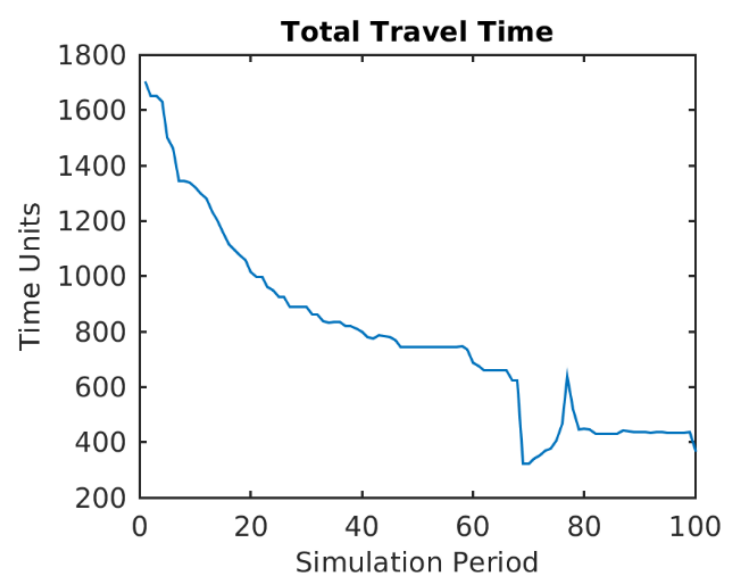

Figure 4: Change in travel time 


\section{ACCEPTED MANUSCRIPT}
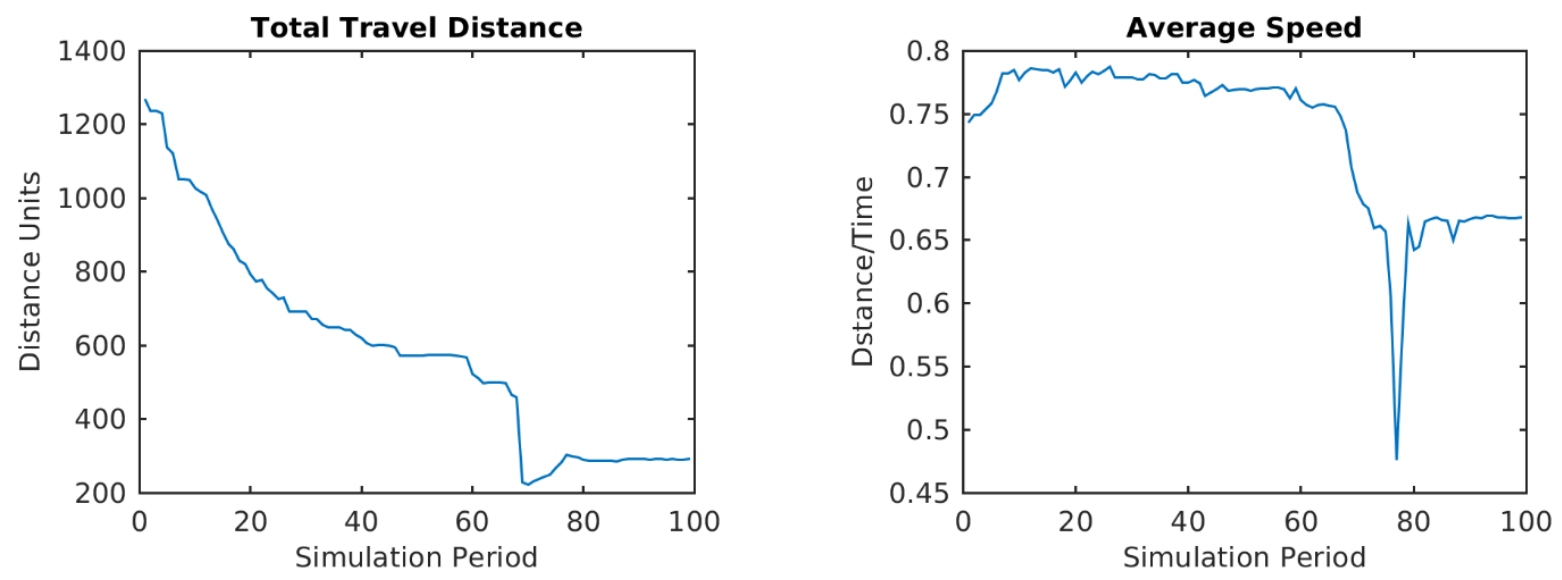

Figure 5: Change in distance travelled and average speed

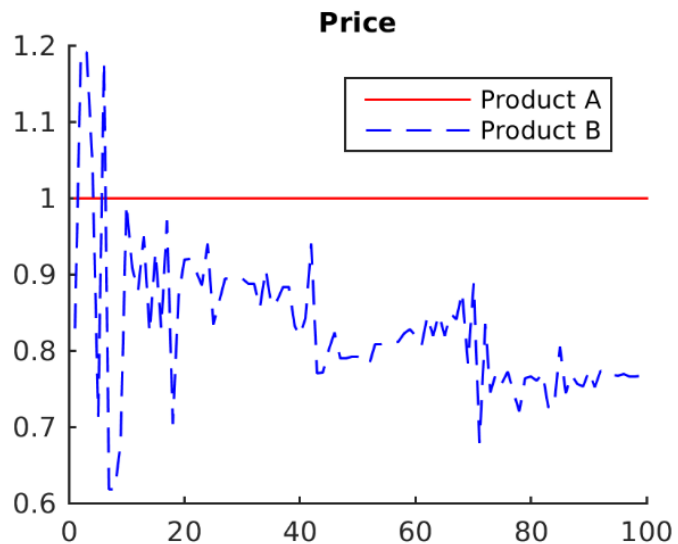

(a)

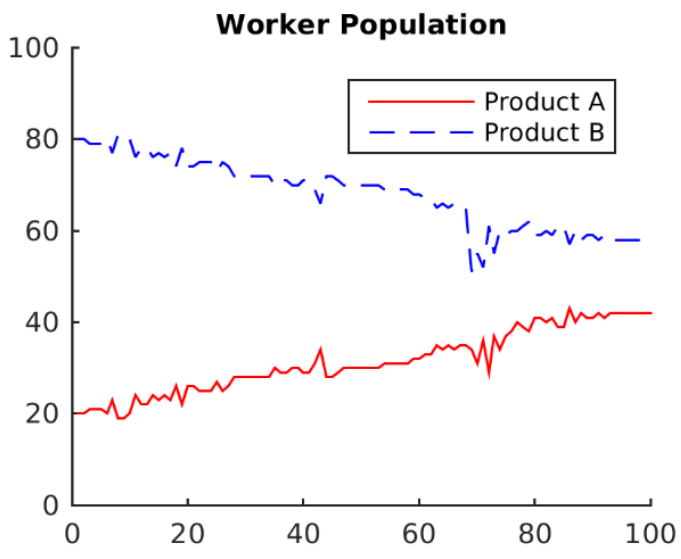

(b)

Figure 6: Change in the Price and worker population 


\section{ACCEPTED MANUSCRIPT}

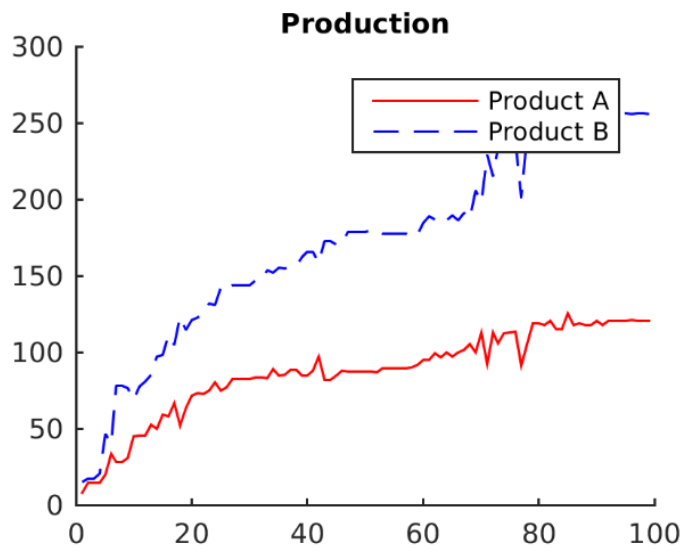

Figure 7: Long-term Product A and Product B production 


\section{ACCEPTED MANUSCRIPT}

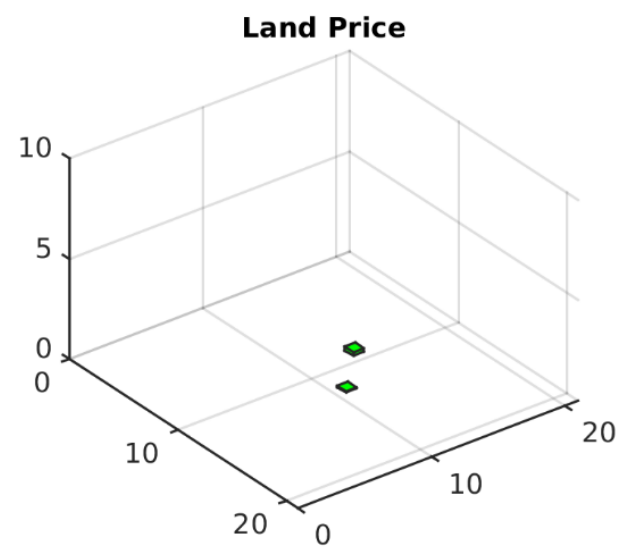

Figure 8: Agent's initial willingness to pay for land

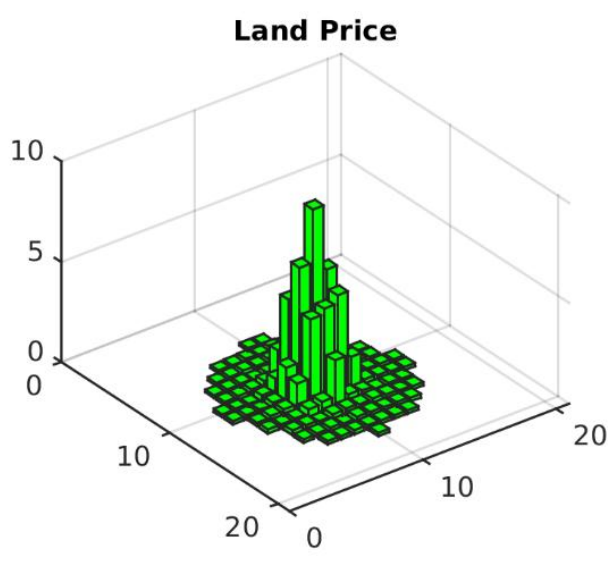

(a)

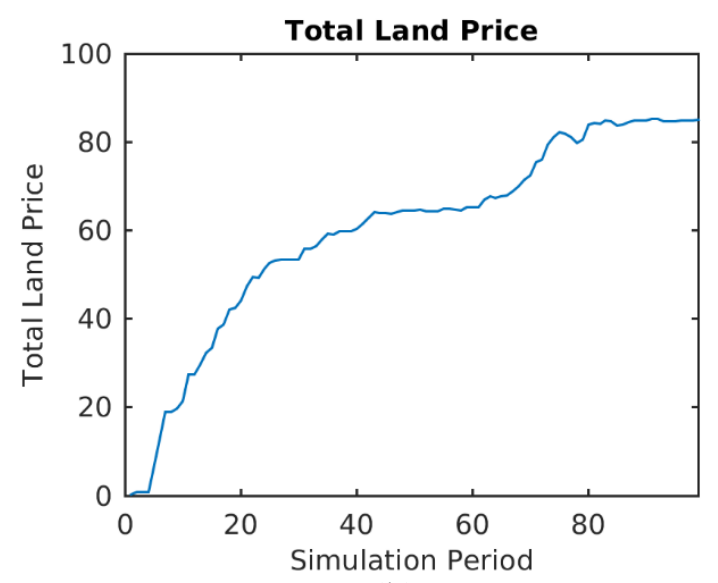

(b)

Figure 9.a \& 9.b: Steady state land price 


\section{ACCEPTED MANUSCRIPT}
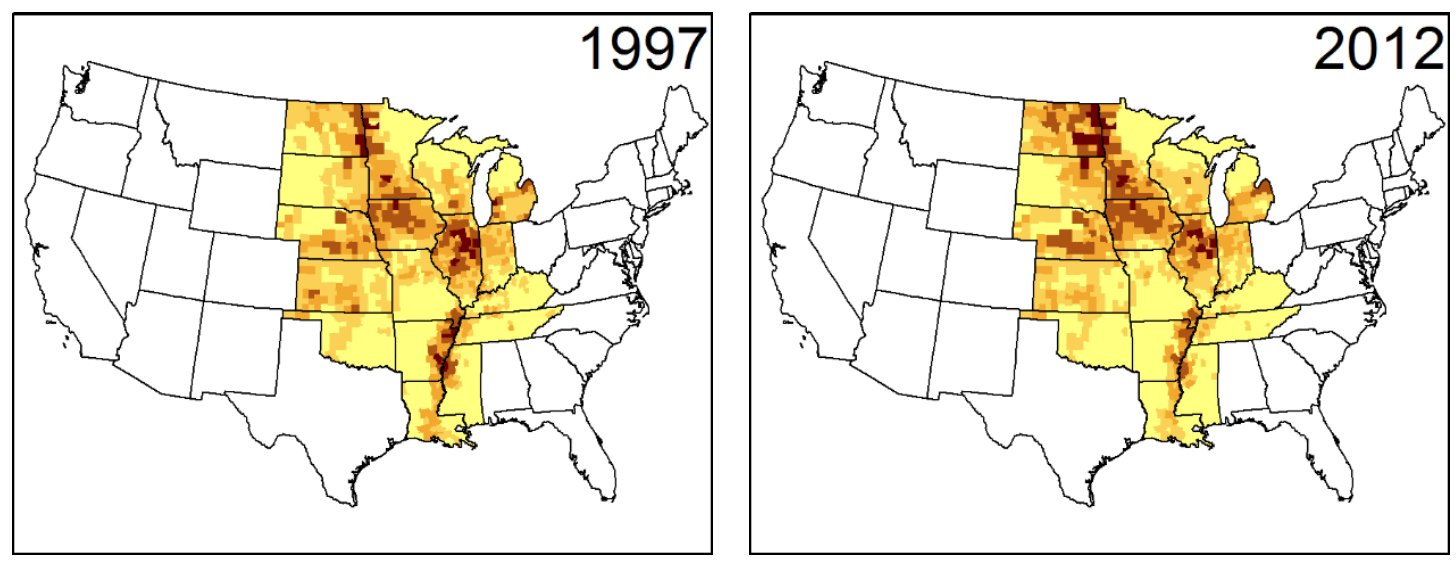

Figure 10: Change in US crops production intensity $(1997,2007)$

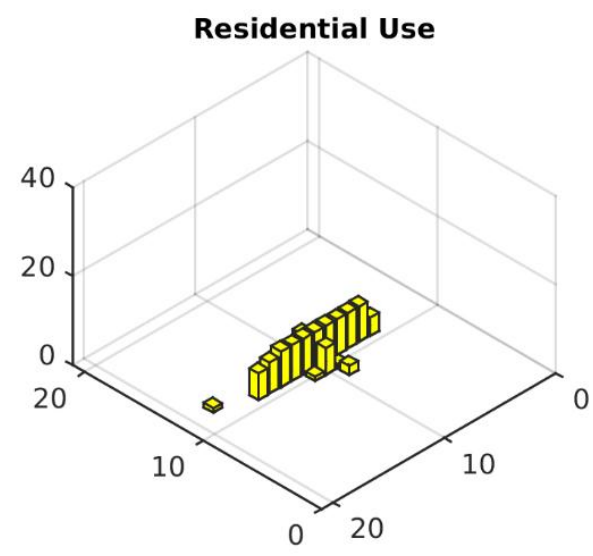

Residence Use

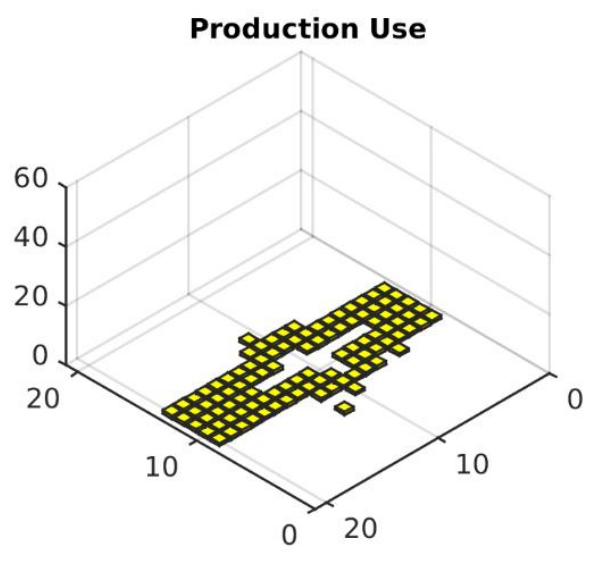

Production Use

Figure 11: Agent's post highway relocation 


\section{ACCEPTED MANUSCRIPT}
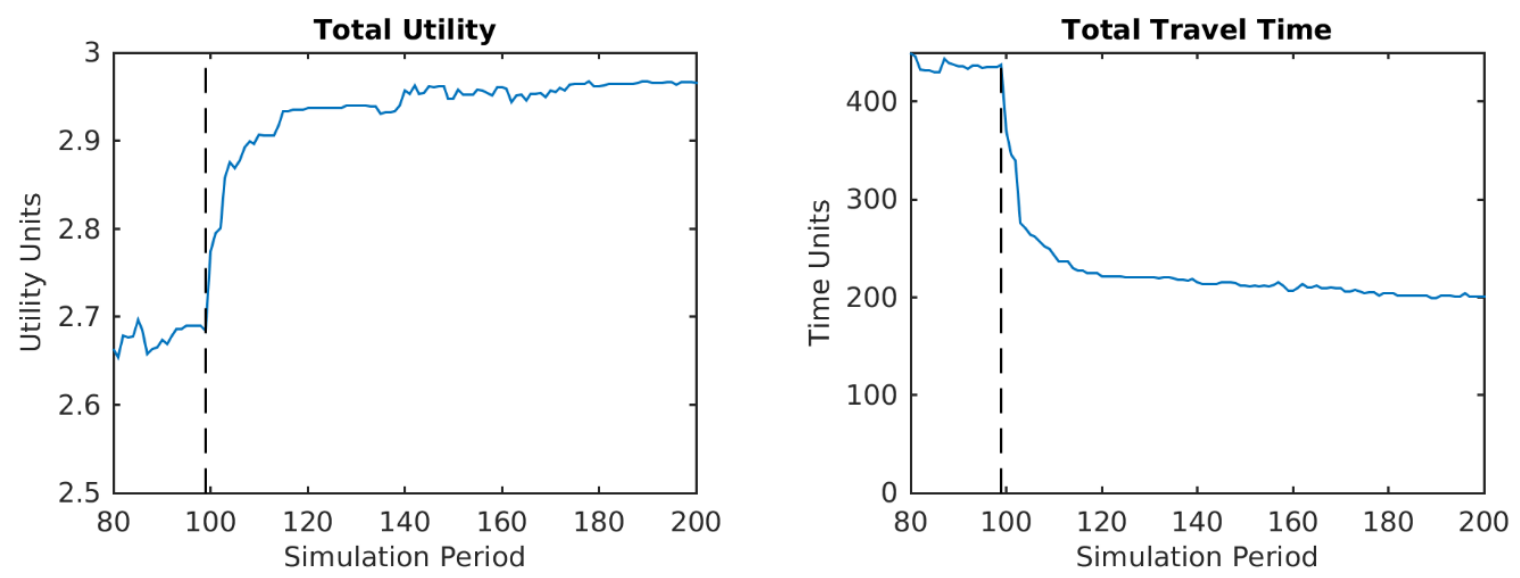

Figure 12: Change in the Total Utility and Travel Time
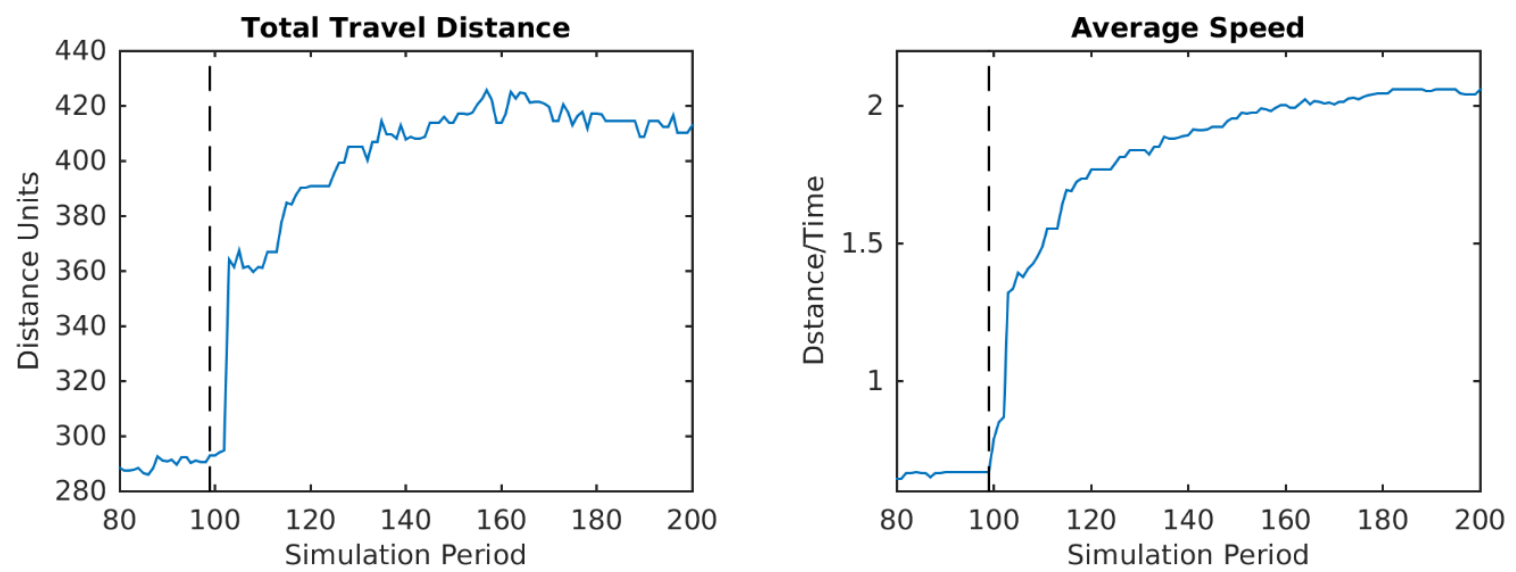

Figure 13: Change in total distance travelled and average speed 


\section{ACCEPTED MANUSCRIPT}

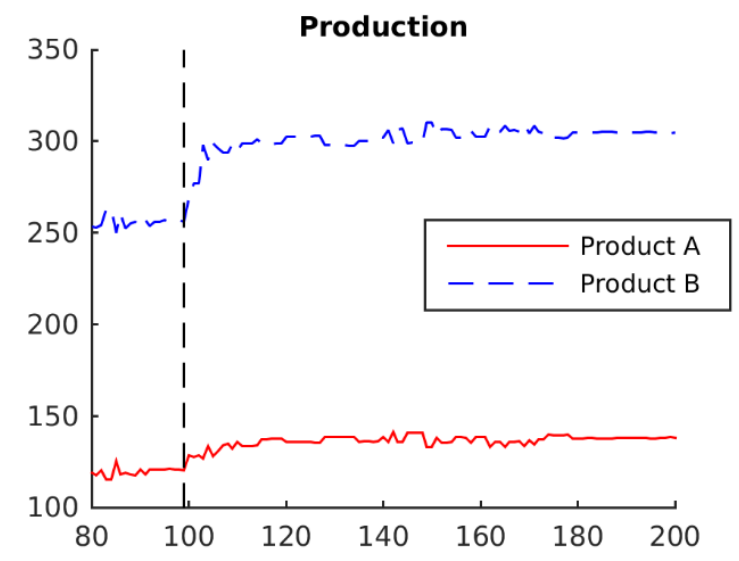

Figure 14: Change in the total production of agents
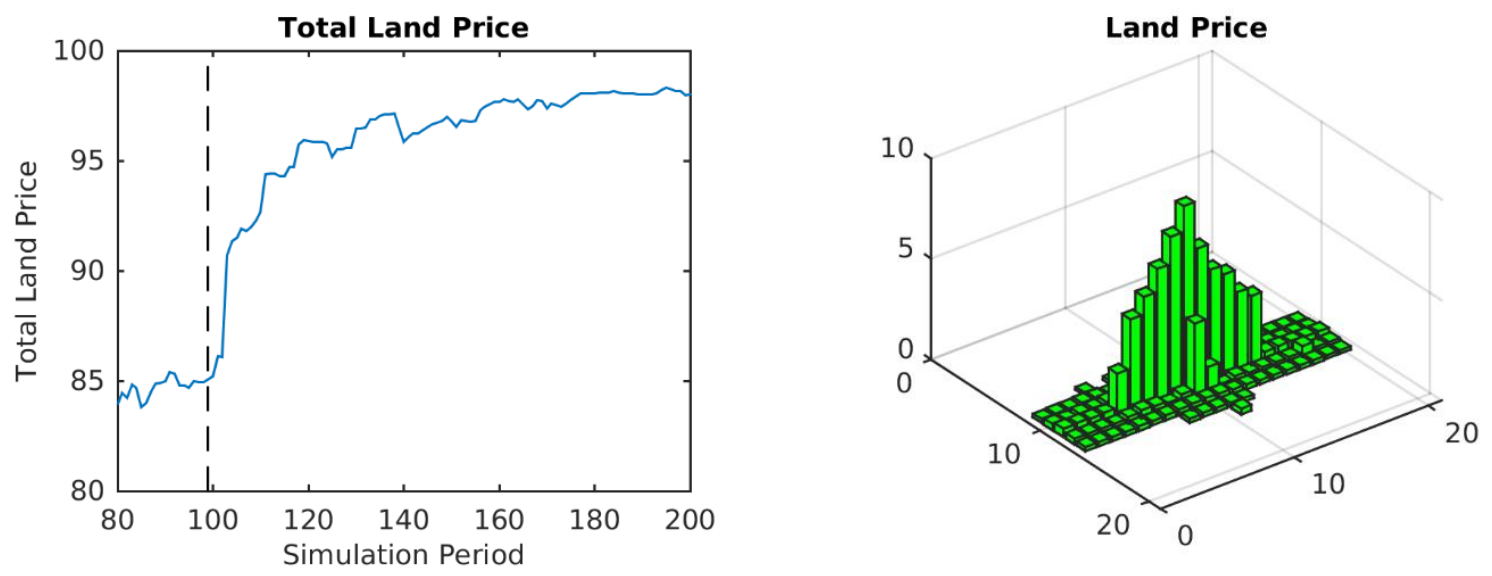

Figure 15: Change in the land price 


\section{ACCEPTED MANUSCRIPT}

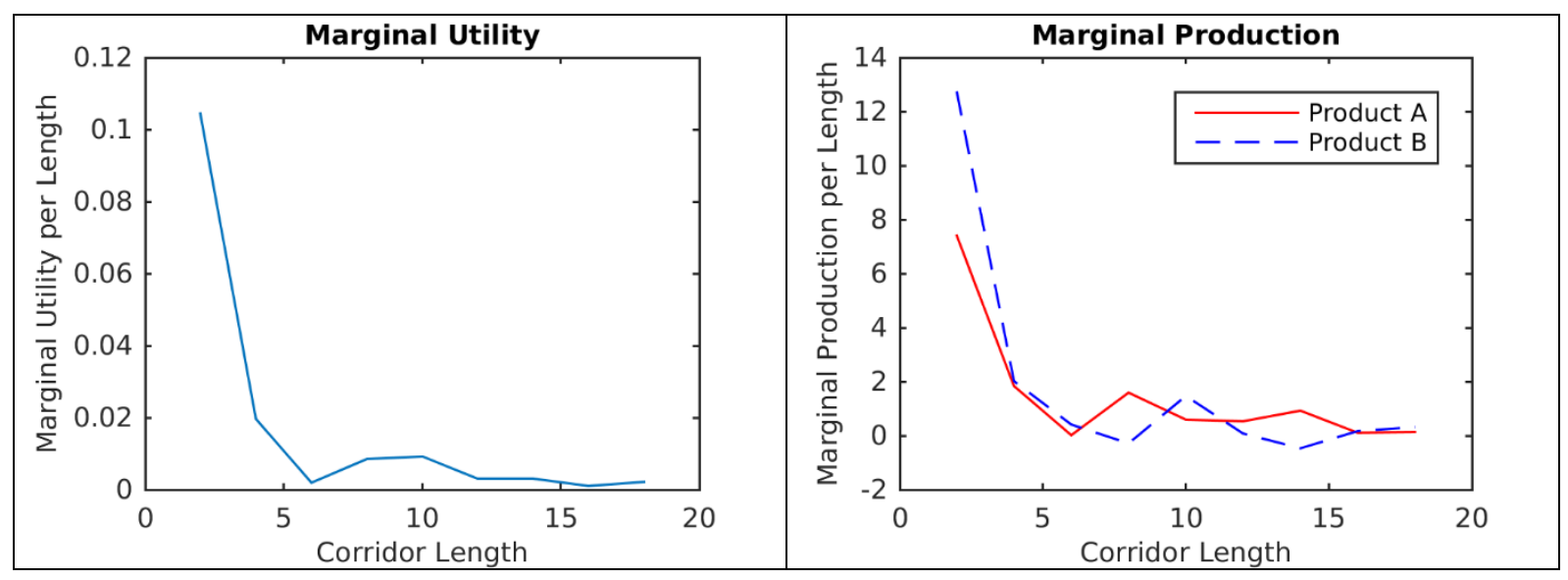

Figure 16: Incremental socioeconomic value of investment in a new traffic corridor

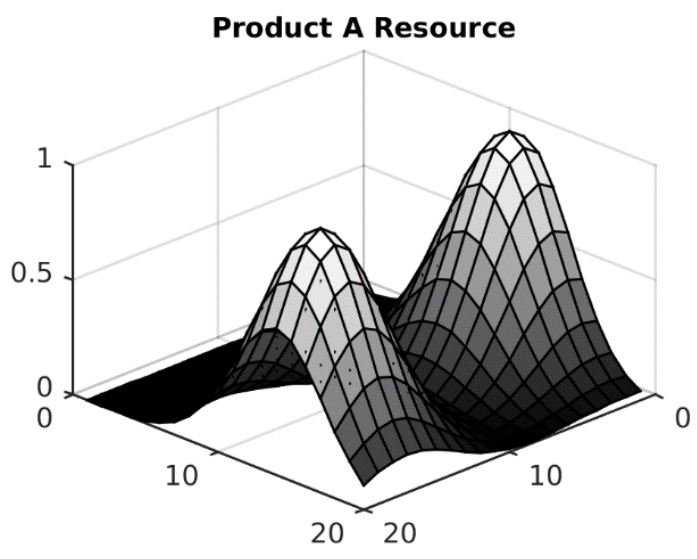

(a)

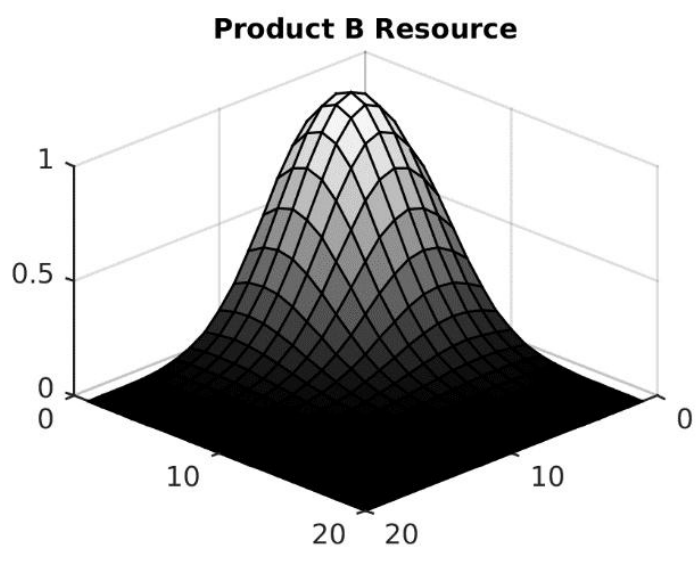

(b)

Figure 17a \& 17b: Non-uniform distribution resources required for production of Product A \& B 


\section{ACCEPTED MANUSCRIPT}

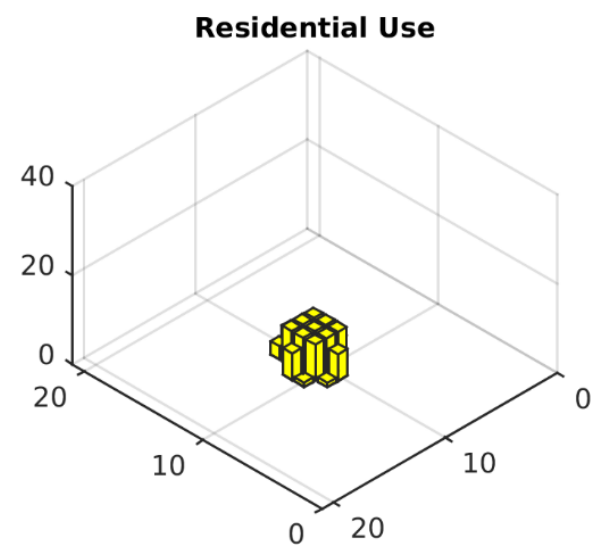

(a)

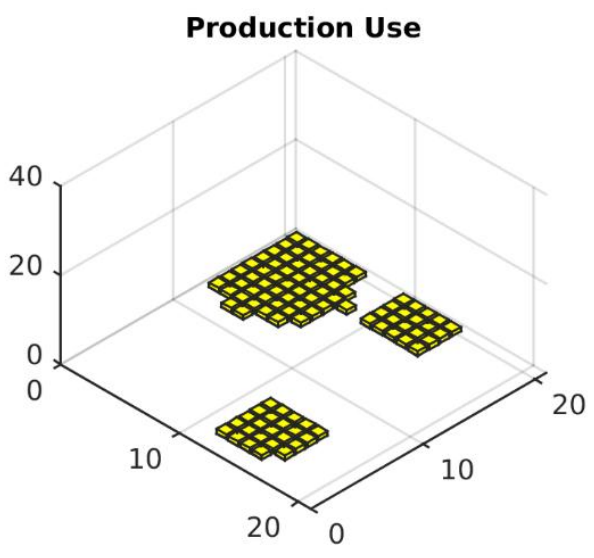

(b)

Figure 18a \& 18b: Spatial residence patterns (a) \& Spatial work patterns (b)

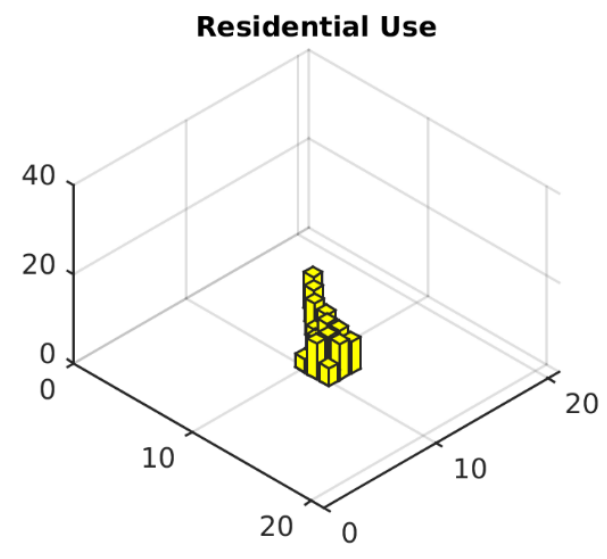

(a)

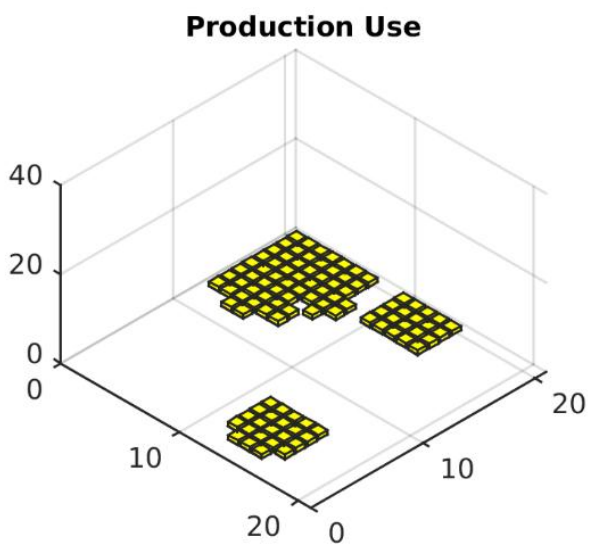

(b)

Figure 19: Agent's post highway relocation 


\section{ACCEPTED MANUSCRIPT}

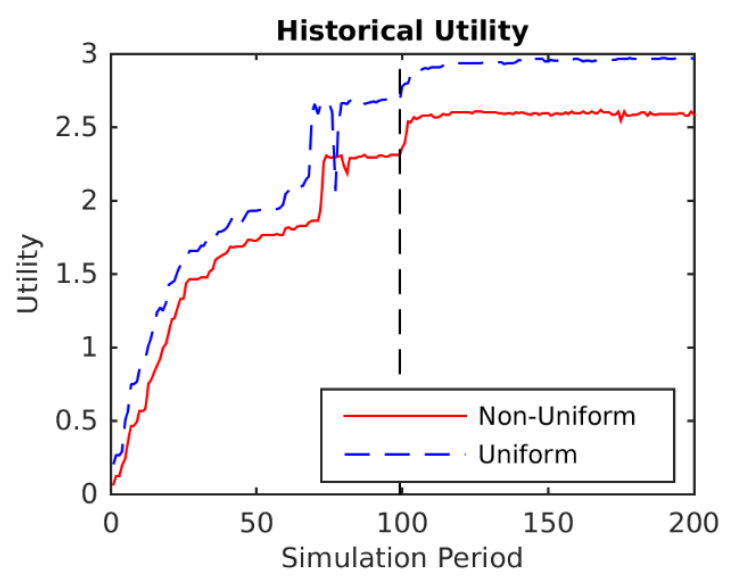

Figure 20: Change in the Total Utility of Non-Uniform and Uniform resource availability cases

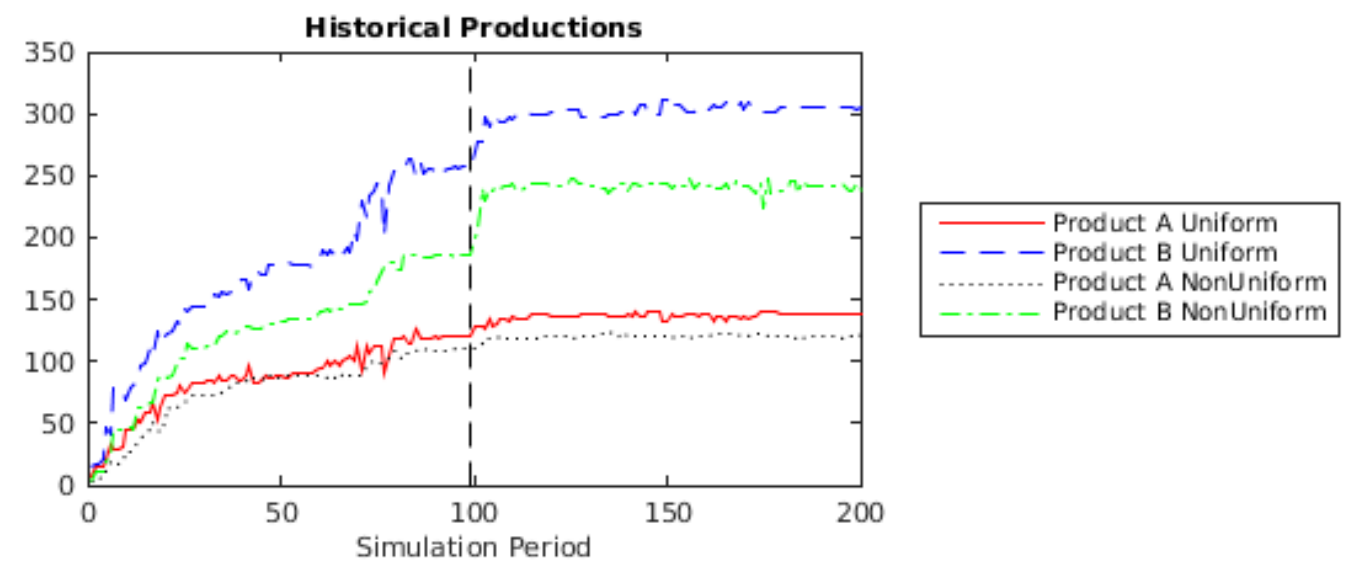

Figure 21: Change in the production levels of Non-Uniform and Uniform resource availability cases 


\section{ACCEPTED MANUSCRIPT}

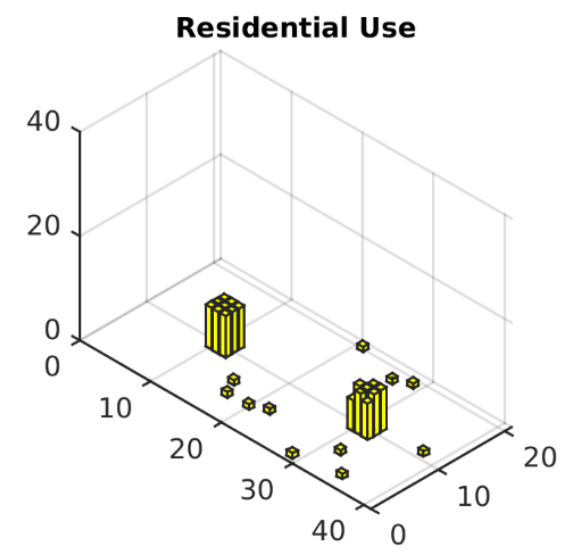

(a)

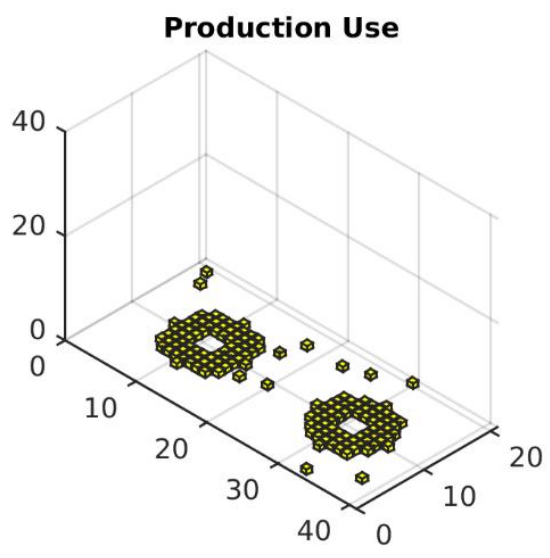

(b)

Figure 22: Spatial residence patterns (a) \& Spatial work patterns (b)

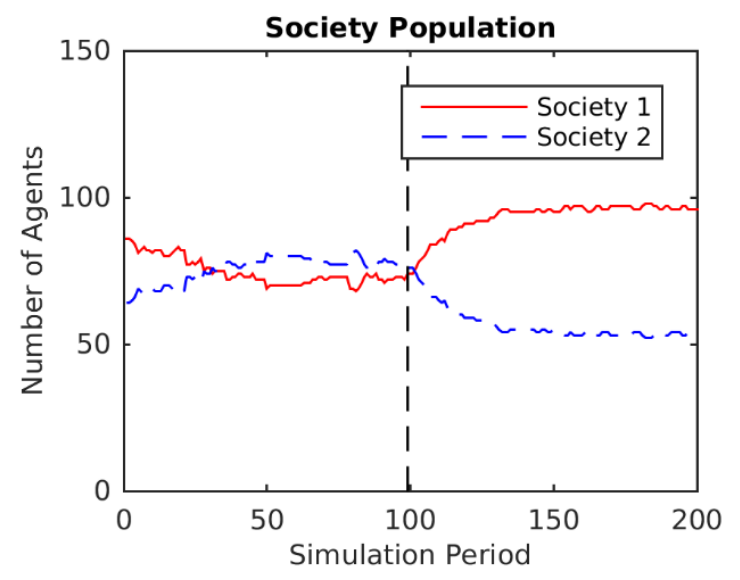

Figure 23: Change in the population of the competing societies 


\section{ACCEPTED MANUSCRIPT}

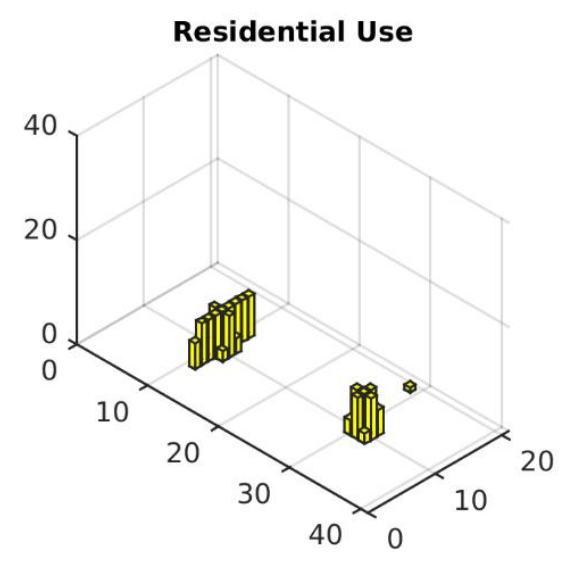

(a)

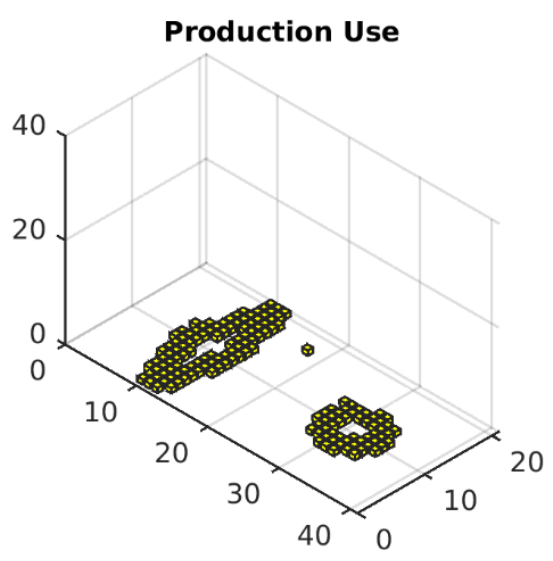

(b)

Figure 24: Agent's post highway relocation 